\title{
Attenuation Correction Effects in Rainfall Estimation at X-Band Dual-Polarization Radar: Evaluation with a Dense Rain Gauge Network
}

\author{
Young-A Oh, ${ }^{1}$ DaeHyung Lee, ${ }^{1}$ Sung-Hwa Jung, ${ }^{2}$ Kyung-Yeub Nam, ${ }^{2}$ and GyuWon Lee ${ }^{1,3}$ \\ ${ }^{1}$ Department of Astronomy and Atmospheric Sciences, Research and Training Team for Future Creative Astrophysicists and \\ Cosmologists, Kyungpook National University, 80 Daehakro, Bukgu, Daegu 41566, Republic of Korea \\ ${ }^{2}$ Radar Analysis Division, Weather Radar Center, Korea Meteorological Administration, 61 16-Gil Yeouidaebangro, Dongjakgu, \\ Seoul 07062, Republic of Korea \\ ${ }^{3}$ Center for Atmospheric REmote Sensing (CARE), Kyungpook National University, 80 Daehakro, Bukgu, \\ Daegu 41566, Republic of Korea \\ Correspondence should be addressed to GyuWon Lee; gyuwon@knu.ac.kr
}

Received 25 December 2015; Accepted 24 April 2016

Academic Editor: Hiroyuki Hashiguchi

Copyright ( 2016 Young-A Oh et al. This is an open access article distributed under the Creative Commons Attribution License, which permits unrestricted use, distribution, and reproduction in any medium, provided the original work is properly cited.

\begin{abstract}
The effects of attenuation correction in rainfall estimation with X-band dual-polarization radar were investigated with a dense rain gauge network. The calibration bias in reflectivity $\left(Z_{H}\right)$ was corrected using a self-consistency principle. The attenuation correction of $Z_{H}$ and the differential reflectivity $\left(Z_{\mathrm{DR}}\right)$ were performed by a path integration method. After attenuation correction, $Z_{H}$ and $Z_{\mathrm{DR}}$ were significantly improved, and their scatter plots matched well with the theoretical relationship between $Z_{H}$ and $Z_{\mathrm{DR}}$. The comparisons between the radar rainfall estimation and the rain gauge rainfall were investigated using the bulk statistics with different temporal accumulations and spatial averages. The bias significantly improves from $70 \%$ to $0 \%$ with $R\left(Z_{H}\right)$. However, the improvement with $R\left(Z_{H}, Z_{\mathrm{DR}}\right)$ was relatively small, from $3 \%$ to $1 \%$. This indicated that rainfall estimation using a polarimetric variable was more robust at attenuation than was a single polarimetric variable method. The bias did not show improvement in comparisons between the temporal accumulations or the spatial averages in either rainfall estimation method. However, the random error improved from $68 \%$ to $25 \%$ with different temporal accumulations or spatial averages. This result indicates that temporal accumulation or spatial average (aggregation) is important to reduce random error.
\end{abstract}

\section{Introduction}

Weather radar has provided useful information about hydrometeors for various meteorological and hydrological applications since its introduction in meteorological observations. Weather radar can observe various parameters of meteorological phenomena with high spatiotemporal resolution over wide observational areas. However, it suffers from many error sources, including radar calibration, beam shielding, attenuation, bright band contamination, beam broadening, and anomalous propagation. Many researchers have studied the characteristics of these error sources and ways to improve the quality of radar data [1-3].

Recently, X-band dual-polarization radar has received significant attention due to its finer resolution, ease of mobility, and lower cost compared to longer wavelength radars. However, the attenuation is a very important issue in $\mathrm{X}$-band, since it is inversely proportional to radar wavelength. The values of the radar parameters associated with the backscattered power, such as reflectivity $\left(Z_{H}\right)$ and differential reflectivity $\left(Z_{\mathrm{DR}}\right)$, can be significantly reduced by attenuation.

The attenuation is caused by absorption and scattering in the medium along the propagation path of the radar beam. The attenuation is severe where the medium is dense and its composition size is large. The attenuation by atmospheric gas molecules is small, being about $1.5 \mathrm{~dB}$ per $100 \mathrm{~km}$ in the Cband [3]. However, media such as rain drops, hail, and melted snow particles can cause significant attenuation, especially in shorter wavelength radar. The amount of attenuation in 
the C-band can reach about $12 \mathrm{~dB}$ due to strong convective cells as compared to the S-band [3]. Furthermore, the attenuation accumulates over distances as a radar beam propagates. The power is frequently lost completely over far ranges. Therefore, it is not possible to monitor and analyze severe weather, such as heavy rains, typhoons, and heavy snows, without the proper correction of the attenuation in the C- or $\mathrm{X}$-band radars.

The attenuation correction has been investigated by many researchers. Tuttle and Rinehart [4] suggested an attenuation correction method using dual-wavelength (S- and X-band) radar measurements with a relationship between specific attenuation $\left(A_{H}\right)$ and $Z_{H}$. Recently, the specific differential propagation phase shift $\left(K_{\mathrm{DP}}\right)$ has been used widely for attenuation correction because $K_{\mathrm{DP}}$ is not affected by radar power calibration, attenuation, and partial beam blocking. In addition, $K_{\mathrm{DP}}$ is less sensitive to the natural variability of drop size distributions (DSDs) in rainfall estimation. Bringi et al. [1] showed that both $A_{H}$ and the specific differential attenuation $\left(A_{\mathrm{DP}}\right)$ are almost linearly related to $K_{\mathrm{DP}}$ through scattering simulations, and these relationships have been accepted by many researchers. However, the coefficients of these relationships derived from the scattering simulations vary significantly with temperature, DSD variability, and the drop deformation model. Park et al. [5] showed that the coefficients of $A_{H}-K_{\mathrm{DP}}$ and $A_{\mathrm{DP}}-A_{H}$ relationships vary greatly from 0.139 to $0.335 \mathrm{~dB}\left({ }^{\circ}\right)^{-1}$ and from 0.114 to $0.174 \mathrm{~dB}^{\circ}\left(^{\circ}\right)^{-1}$ in the X-band, respectively, due to changes in temperatures and the different drop deformation models.

While $K_{\mathrm{DP}}$ has many advantages in the attenuation correction as described above, estimating $K_{\mathrm{DP}}$ from the measured total differential phase shift $\left(\Psi_{\mathrm{DP}}\right)$ is challenging because of the backscatter differential phase shift $(\delta)$ and the measurement errors for $\Psi_{D P}$ [1]. Scarchilli et al. [6] used an iteration method with a $\delta-Z_{\mathrm{DR}}$ relationship to remove $\delta$ from $\Psi_{\mathrm{DP}}$ and corrected the attenuation using estimated $K_{\mathrm{DP}}$ in the C-band. Anagnostou et al. [7], Kalogiros et al. [8], and Chang et al. [9] used an iteration method in the X-band. As a different method for removing $\delta$, Hubbert and Bringi [10] separated $\delta$ and the differential propagation phase $\left(\Phi_{\mathrm{DP}}\right)$ from $\Psi_{\mathrm{DP}}$ through an iterative filtering technique (FIR) and calculated the hail signal from $\delta$. Park et al. [5] also used the same filtering technique to extract $\Phi_{\mathrm{DP}}$ for correcting the attenuation and the differential attenuation in the X-band. Recently, Mishra et al. [11] investigated dual-polarimetric products and three types of rainfall estimation results with high spatiotemporal resolution data from X-band radar, Sband radar, and disdrometer data with an intercomparison and T-matrix simulation method [12]. Mishra et al. [11] used a very similar attenuation correction process in their work, where $A_{H}$ was calculated by an FIR filtered $\Phi_{\mathrm{DP}}$, and $A_{\mathrm{DP}}$ was calculated by an $A_{\mathrm{DP}}-A_{H}$ relationship based on a selfconsistency method.

Two rainfall estimation methods, $R\left(Z_{H}\right)$ and $R\left(Z_{H}, Z_{\mathrm{DR}}\right)$, were used for evaluation of the attenuation correction effect. The self-consistency based correction of the attenuation and the differential attenuation from the FIR filtered $\Phi_{\mathrm{DP}}$ were used to improve the accuracy in the rainfall estimation methods by X-band polarimetric radar. The accuracy evaluation of the rainfall estimation methods was performed by comparisons with rain gauge measurements with high spatial resolution. However, there were instrumental uncertainties and errors in the representativeness of the rain gauge measurements. The instrumental error has several sources, including the gauge calibration, wind effects, and wetting/evaporation loss $[13,14]$. The representativeness error is linked with the spatial sampling area and the temporal accumulation of the rain gauge [15]. Habib et al. [16] investigated sampling error of the tipping bucket gauge as function of accumulation times in a simulation study. Ciach [17] verified local random errors in the tipping bucket gauge through experimental data. Habib et al. [18] investigated the correlation with separation distances in a rain gauge cluster. In this study, we considered the calibration effects in the instrumental error of the rain gauge. Instrumental error from the calibration effect was removed by laboratory experiments to provide more accurate and reliable references. The representativeness error was investigated by the temporal accumulation and spatial average of rainfall amount.

In Section 2, the radar and rain gauge data used in this study are presented. The methods for the attenuation correction by $\Phi_{\mathrm{DP}}$, the rainfall estimation and its verification, and the analysis of the natural variability of rain fields using rain gauge data are described in Section 3. The analysis results are shown in Section 4. The results are summarized in Section 5.

\section{Data}

2.1. Radar Data. The radar data from the X-band dualpolarimetric radar (NIMS-XPOL) of the National Institute of Meteorological Sciences (NIMS) was used in this study. The general characteristics of the NIMS-XPOL data are shown in Table 1. The NIMS-XPOL can be installed onto a five-ton truck bed (Figure 1(a)) and mounted on a steel tower bed (Figure 1(b)).

The NIMS-XPOL was operated during June 2010 at Muan-gun, Jeollanam-do, which is on the southwest coast of Korea (latitude $=\mathrm{N} 35.0940^{\circ}$, longitude $=\mathrm{E} 126.285^{\circ}$ ) for the observation of heavy rains during the summer monsoon season. The rain estimation in Section 3.2 was performed with the NIMS-X radar data collected during 5.5 hours, from 1600 UTC to 2130 UTC, on July 10, 2010. During this rain event, the NIMS-X was mounted on a steel tower bed in the Muan-gun observation center to minimize the effect of beam shielding and ground clutter, and a full volume scan with 14 Plan Position Indicators (PPIs) was performed every $2.5 \mathrm{~min}$. The gate spacing was $150 \mathrm{~m}$, and the Pulse Repetition Frequency (PRF) was $999 \mathrm{~Hz}$. And the total rainfall amount was over $50 \mathrm{~mm}$. The evolution of the rain field is shown in Figure 2. The echoes moved toward the northeast, and the small and weak rain cells near the radar site at 1601 UTC were replaced by the strong convective cells approaching from the southwest. 
TABLE 1: General characteristics of the NIMS-XPOL radar [21].

\begin{tabular}{lcc}
\hline & X-band polarimetric mobile Doppler weather radar (ARC-X250MP) specification & Magnetron \\
& Type & 250 \\
Transmitter & Peak power $(\mathrm{kW})$ & 9,360 \\
& Frequency $(\mathrm{MHz})$ & $0 \sim 2,500$ \\
\hline \multirow{4}{*}{ Antenna } & PRF $(\mathrm{MHz})$ & 2.44 \\
& Diameter $(\mathrm{m})$ & Orthogonal linear simultaneous H \& V \\
& Polarization & 0.95 \\
Data processing & Beamwidth $\left(^{\circ}\right)$ & $>43$ \\
& Gain $(\mathrm{dB})$ & $3000 @ 1000 \mathrm{PRF}$ \\
& Number of gates & $30 \mathrm{~m}$ to $1000 \mathrm{~m}$ \\
\hline
\end{tabular}

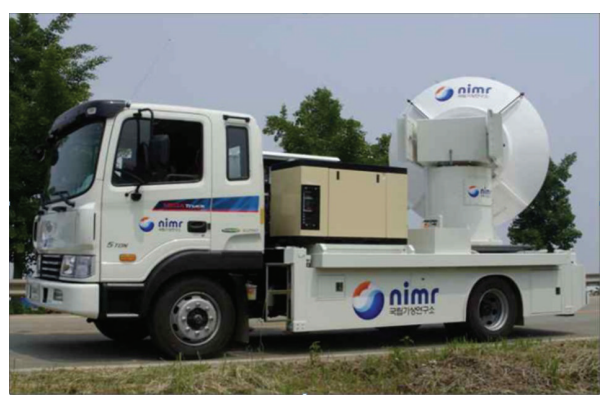

(a)

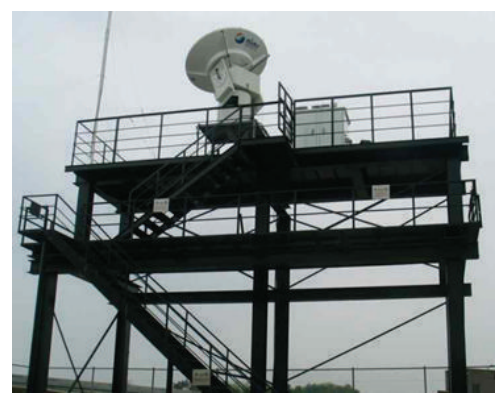

(b)

FIgURE 1: Photographs of the NIMS-XPOL radar installed onto (a) a truck bed and (b) a steel tower bed (courtesy of NIMS).

2.2. Rain Gauge Data. The rain gauge data was collected by ten tipping bucket (TB) rain gauges operated by the Kyungpook National University (KNU), Korea. The tip size of all of the gauges was $0.2 \mathrm{~mm}$, and the diameter of the receiving orifice was $15.39 \mathrm{~cm}$. The time resolution was $0.5 \mathrm{~s}$, and the data was recorded based on the event (tipping) time. To compare with the estimated rain rate $(R)$ from the NIMSXPOL radar, the rain accumulation from ten gauges was collected during the month of July 2010 near Unnam-myeon, which is located at a distance of about $16 \mathrm{~km}$ at $160^{\circ}$ azimuth angle from the NIMS-XPOL radar. The area was only slightly affected by beam shielding of the NIMS-XPOL. Considering the geographical situation and the limited locations for the installation, all gauges were installed on the rooftops of buildings. Figure 3 shows the location of the NIMS-XPOL and the deployment of the ten gauges ( $\mathrm{R}$ is the radar site, and a number represents a gauge location). The total rainfall amount for the month at each gauge site is shown in Table 2. At all gauge sites, the total rainfall accumulation was over $300 \mathrm{~mm}$ for the month. The rainfall amount measured during the same period with the NIMS-XPOL radar data used in the rainfall estimation was about $50 \mathrm{~mm}$ per 5.5 hours (see Table 2).

The instrumental biases of all gauges were calculated through an ideal experiment using laboratory and field observations for 9 months from October 2009 to June 2010 (except April 2010) at KNU. The rain gauge dataset was corrected for the instrumental bias prior to the detailed analysis.

\section{Methodology}

3.1. Attenuation Correction Algorithm Using Differential Propagation Phase Shift. The attenuation correction algorithm was performed by the procedure as shown in Figure 4, which included (1) quality control of the radar data, (2) estimation of $\Phi_{\mathrm{DP}}$, (3) calculation of the attenuation amount, and (4) the attenuation correction of $Z_{H}$ and $Z_{\mathrm{DR}}$.

As a part of the quality control of the radar data, $Z_{H}$ and $Z_{\text {DR }}$ were corrected for instrumental biases. $Z_{H}$ calibration bias of about $3.7 \mathrm{~dB}$ was obtained by comparison with the reflectivity from the particle size velocity disdrometer (PARSIVEL) and from the NIMS-XPOL radar. The $Z_{\mathrm{DR}}$ calibration bias of $-1.5 \mathrm{~dB}$ was calculated from the vertical pointing data [19]. The isolated point echo shows that the $Z_{H}$ values in their surrounding pixels existed by less than $50 \%$ of the total pixels to be removed. The $\rho_{\mathrm{HV}}$ threshold of 0.9 was applied to the entire radar measurement field.

After applying the quality control measures, $\Phi_{\mathrm{DP}}$ was estimated from measured $\Psi_{\mathrm{DP}}$ by eliminating $\delta$ and the observational noise through an iterative filtering technique. In this study, the 20th FIR filter of Hubbert and Bringi [10] was used. This filter preserved a monotonic increasing trend of $\Phi_{\mathrm{DP}}$ due to the propagation medium, while it removed the 


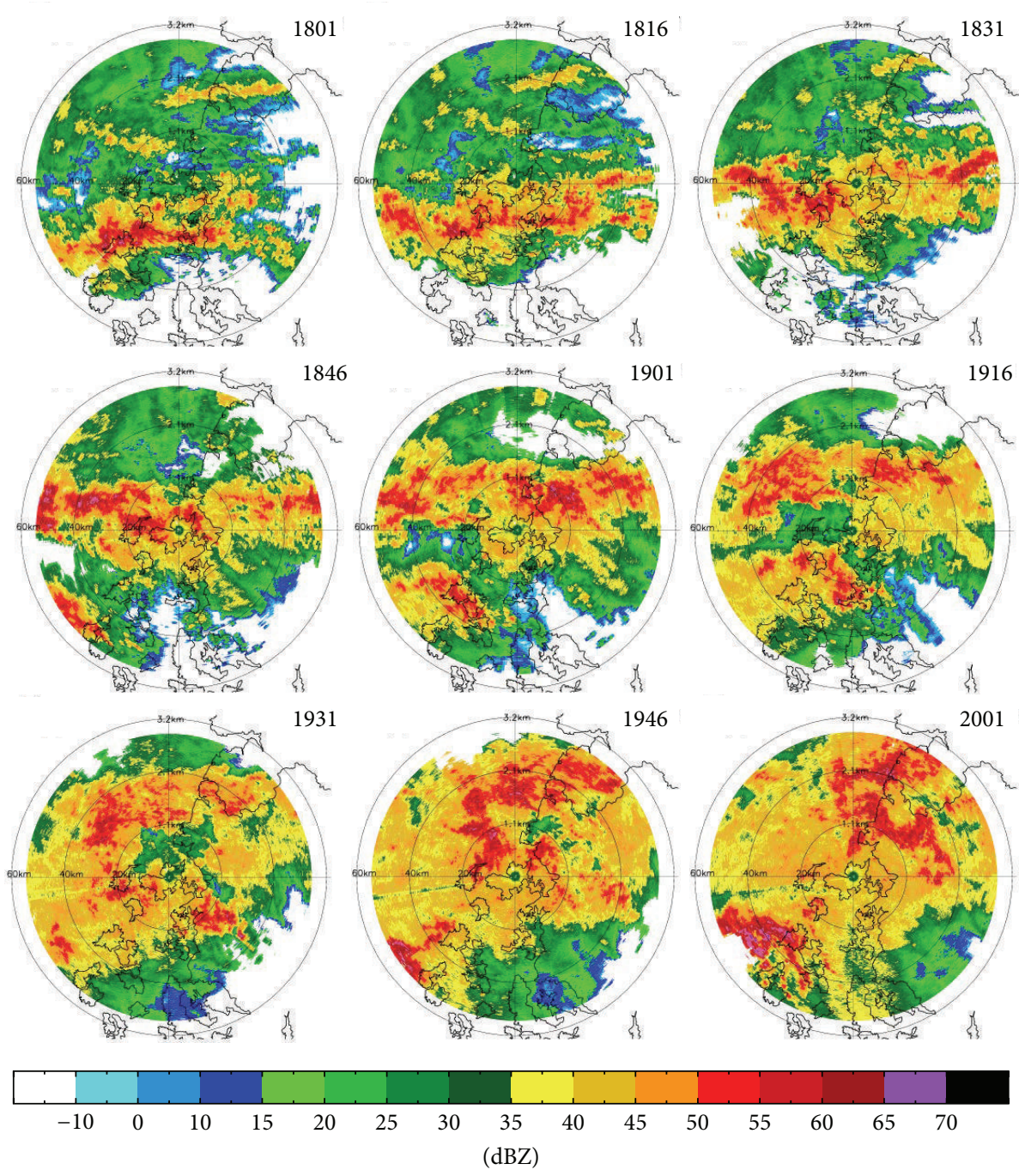

FIGURE 2: PPI images of attenuation corrected $Z_{H}$ from 1801 UTC, July 10, 2010, with an interval of 15 min.

TABLE 2: Total rainfall amount for the month and per analysis time.

\begin{tabular}{|c|c|c|c|c|c|c|c|c|c|c|}
\hline Gauge ID & RG1 & RG2 & RG3 & RG4 & RG5 & RG6 & RG7 & RG8 & RG9 & RG10 \\
\hline Total rainfall amount for the month $(\mathrm{mm})$ & 321.4 & 371.7 & 330.8 & 313.9 & 321.8 & 342.6 & 332.1 & 323.9 & 374.3 & 324.5 \\
\hline Total rainfall amount for the analysis time (mm) & 47.6 & 56.0 & 51.0 & 52.9 & 55.2 & 57.1 & 54.4 & 54.4 & 51.3 & 53.1 \\
\hline
\end{tabular}

smaller scale fluctuations compared to the filtering window $(2.5 \mathrm{~km}$ when the gate size is $0.125 \mathrm{~m})$ due to $\delta$ and the observation noise. Hubbert and Bringi [10] also found that repeating the filtering process 10 times produced good results.

The additional problem in the estimation of $\Phi_{\mathrm{DP}}$ was the variable offset of $\Phi_{\mathrm{DP}}$. $\Phi_{\mathrm{DP}}$ observation can be noisy in near range. Radar, in general, has $\Phi_{\mathrm{DP}}$ offset to avoid observing negative value of $\Phi_{\mathrm{DP}}$ in near range. Ideally, the offset should not change with the azimuthal angles. However, the offsets of measured $\Psi_{D P}$ of the NIMS-X varied with the azimuthal angles, and $\Phi_{\mathrm{DP}}$ values decreased near the radar when rain cells existed above the radar. Therefore, the offset was determined as the minimum value of $\Phi_{\mathrm{DP}}$ within $3 \mathrm{~km}$ of the radar, and estimated filtered $\Psi_{\mathrm{DP}}$ was adjusted accordingly.

The calculation of $A_{H}$ and $A_{\mathrm{DP}}$ was based on the following two relationships $[1,5,20]$ :

$$
\begin{aligned}
& A_{H}(r)=\sigma K_{\mathrm{DP}}(r), \\
& A_{\mathrm{DP}}(r)=\varepsilon A_{H}(r),
\end{aligned}
$$

where $A_{H}(r)$ and $A_{\mathrm{DP}}(r)$ are the specific attenuation and the specific differential attenuation at range $r$ from the radar, 


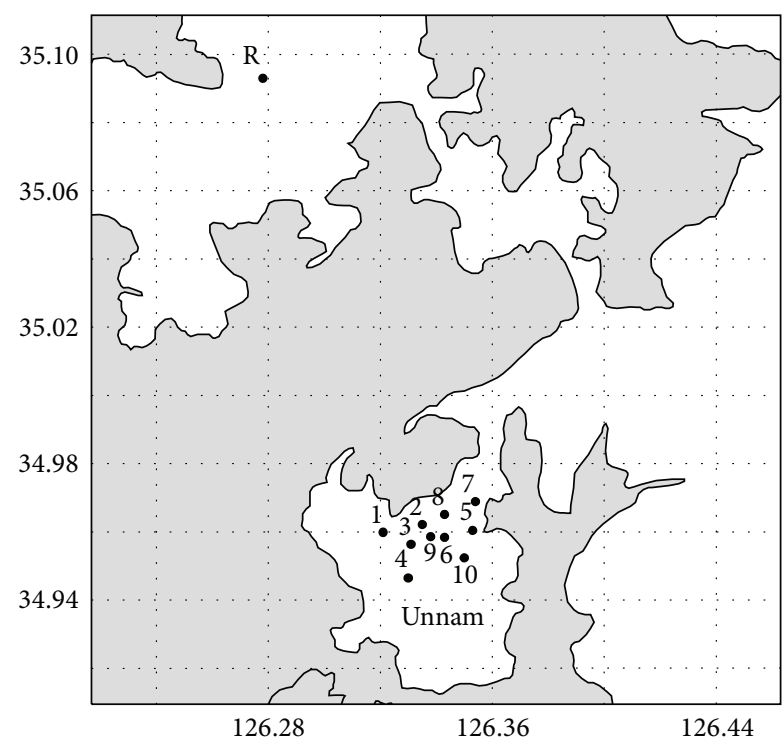

FIGURE 3: Layout of NIMS-XPOL and the 10 rain gauges near Unnam-myeon, Muan-gun, Jeollanam-do, Korea. $\mathrm{R}$ shows the location of the NIMS-XPOL; the numbered points indicate the observational sites of the 10 rain gauges.

respectively. $K_{\mathrm{DP}}(r)$ is the specific differential one-way phase shift calculated using the following equation:

$$
K_{\mathrm{DP}}(r)=\frac{\Phi_{\mathrm{DP}}\left(r_{2}\right)-\Phi_{\mathrm{DP}}\left(r_{1}\right)}{2\left(r_{2}-r_{1}\right)},
$$

where $r$ is between $r_{1}$ and $r_{2}$. The coefficients $\sigma(=0.3445)$ and $\varepsilon(=0.1705)$ were derived from $A_{H}, A_{\mathrm{DP}}$, and $K_{\mathrm{DP}}$ obtained by scattering simulations with the DSDs data collected by the Precipitation Occurrence Sensor System (POSS) from March to September of 2001 in Pusan, Korea [21]. The total path integrated attenuation and differential attenuation were calculated with $\Phi_{\mathrm{DP}}$ by integrating the following:

$$
\begin{aligned}
2 \int_{0}^{r} A_{H}\left(r^{\prime}\right) d r^{\prime} & =\sigma \Phi_{\mathrm{DP}}(r), \\
2 \int_{0}^{r} A_{\mathrm{DP}}\left(r^{\prime}\right) d r^{\prime} & =\varepsilon \times 2 \int_{0}^{r} A_{H}\left(r^{\prime}\right) d r^{\prime} .
\end{aligned}
$$

Number 2 in the equations indicates that the values are twoway values.

Finally, the measured reflectivity $Z_{H \text {-meas }}(r)$ [dBZ] and the differential reflectivity $Z_{\mathrm{DR} \text {-meas }}(r)[\mathrm{dB}]$ at $r$ were corrected with the calculated two-way path integrated attenuation and differential attenuation:

$$
\begin{gathered}
Z_{H-\text { corr }}(r)=Z_{H \text {-meas }}(r)+2 \int_{0}^{r} A_{H}\left(r^{\prime}\right) d r^{\prime}, \\
Z_{\mathrm{DR} \text {-corr }}(r)=Z_{\text {DR-meas }}(r)+2 \int_{0}^{r} A_{\mathrm{DP}}\left(r^{\prime}\right) d r^{\prime} .
\end{gathered}
$$

3.2. Radar Rain Estimation and Comparison with Rain Gauge Data. A comparison between estimated $R$ from the radar

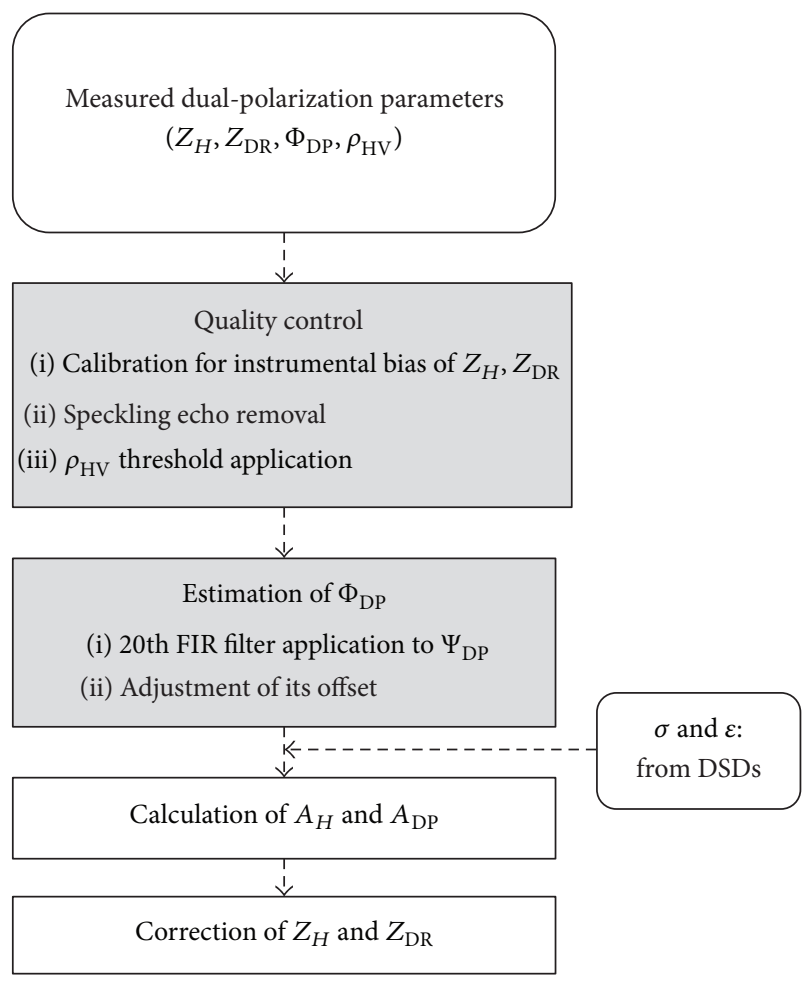

FIGURE 4: The schematic diagram of the attenuation correction algorithm.

parameters and the rain rate $(G)$ from the rain gauge data was performed to evaluate the attenuation correction algorithm. In addition to the rain attenuation, the difference between $R$ and $G$ was caused by the errors due to the instrumental uncertainty and representativeness errors of the rain gauge data, the radar observational noise, and the errors in the radar rainfall estimation. The bias due to the instrumental uncertainty in gauge data was removed by properly calibrating the gauges through laboratory tests and a gauge intercomparison. The representativeness errors were due to the mismatch of the sampling area (volume) between the gauge and the radar. The random error in the gauge data could be minimized by time and areal integration. The errors due to the measurement noise in the radar data could be reduced in a similar manner. The time offset between the rain gauge and the radar sampling area was ignored due to the close distance (about $16 \mathrm{~km}$ ) and the low elevation angle $\left(3^{\circ}\right)$.

Therefore, $R$ and $G$ were derived with two different radar sampling areas and with increasing accumulation time.

(1) $R\left(0.38 \mathrm{~km}^{2}\right)$ versus $G\left(0.07 \mathrm{~m}^{2}\right) . R\left(0.38 \mathrm{~km}^{2}\right)$ was estimated from the average radar measurement with 9 pixels $\left(0.38 \mathrm{~km}^{2}\right.$ at $16 \mathrm{~km}$ range). The gauge rainfall rate $G\left(0.07 \mathrm{~m}^{2}\right)$ was derived from the rainfall accumulation from an individual rain gauge that had a sampling area of $0.07 \mathrm{~m}^{2}$.

(2) $R\left(6 \mathrm{~km}^{2}\right)$ versus $G\left(6 \mathrm{~km}^{2}\right) . R\left(6 \mathrm{~km}^{2}\right)$ was estimated from the areal averaged radar parameters at a $1.6 \mathrm{~km} \times 3.1 \mathrm{~km}$ radar 
TABLE 3: Two rain rate retrieval algorithms and boundary conditions [22].

\begin{tabular}{ccccc}
\hline & \multicolumn{2}{c}{$R\left(Z_{H}\right)=\alpha Z_{H}^{\beta}$} & \multicolumn{2}{c}{$R\left(Z_{\mathrm{DR}}\right)=\alpha Z_{H}^{\beta} 10^{0.1 \gamma Z_{\mathrm{DR}}}$} \\
& $Z>35 \mathrm{dBZ}$ & $Z<35 \mathrm{dBZ}$ & $Z>35 \mathrm{dBZ}, Z_{\mathrm{DR}}>0.3 \mathrm{~dB}$ & $1.45 \times 10^{-2}$ \\
\hline$\alpha$ & $3.53 \times 10^{-2}$ & $3.83 \times 10^{-2}$ & $1.03 \times 10^{-2}$ & $8.90 \times 10^{-1}$ \\
$\beta$ & $6.21 \times 10^{-2}$ & $6.08 \times 10^{-2}$ & $9.85 \times 10^{-1}$ & -5.295 \\
$\gamma$ & - & - & -6.479 & $-295 \mathrm{~dB}$ \\
\hline
\end{tabular}

measurement resolution. $G\left(6 \mathrm{~km}^{2}\right)$ was the average value of $G\left(0.07 \mathrm{~m}^{2}\right)$ from the ten gauges within the same area.

Estimated $R$ from radar parameters was calculated with two rain estimators as shown in Table 3. These rain estimators were derived by a least squares fit with the theoretical $Z_{H}$, $Z_{\mathrm{DR}}$, and $R$ obtained by scattering simulations with the DSD data collected by POSS from March to September of 2001 in Pusan, Korea [21]. To improve the estimation accuracy, each estimator was derived for two categories. The reflectivity threshold of $35 \mathrm{dBZ}$ was used as a standard stratiform/convective rain classification [22]. The $Z_{\mathrm{DR}}$ threshold of $0.3 \mathrm{~dB}$ was used to minimize the effect of the $Z_{\mathrm{DR}}$ measurement noise. The PPI data with an elevation angle of $3^{\circ}$ was used to suppress the beam shielding and ground clutter. The $Z_{H}$ and $Z_{\mathrm{DR}}$ fields from the radar were smoothed by the linear average of values at $3 \times 3$ pixels to reduce the observational noise.

The bias in $G$ from the ten rain gauges was corrected by the laboratory test and the intercomparison with field data. The detail is presented in Appendix. To evaluate the attenuation correction algorithm and verify the rainfall retrieval accuracy, the comparisons of $R$ and $G$ were represented by the general statistics such as normalized bias (NB), normalized standard deviation (NSD), root-mean square error (rmse), relative rms error (r_rmse), and Spearman correlation (corr.) as follows:

$$
\begin{aligned}
& \mathrm{NB}_{R-G}(\Delta t)=\frac{(1 / n) \sum_{k=0}^{n-1}\left[R_{k}(\Delta t)-G_{k}(\Delta t)\right]}{\bar{G}(\Delta t)}, \\
& \mathrm{NSD}_{R-G}(\Delta t)=\frac{\sqrt{(1 / n) \sum_{k=0}^{n-1}\left[R_{k}(\Delta t)-G_{k}(\Delta t)\right]^{2}}}{\bar{G}(\Delta t)}, \\
& \operatorname{rmse}_{R-G}(\Delta t)=\sqrt{\frac{\sum_{k=0}^{n-1}\left[R_{k}(\Delta t)-G_{k}(\Delta t)\right]^{2}}{n}}, \\
& \operatorname{rmse}_{R-G}(\Delta t)=\sqrt{\frac{\sum_{k=0}^{n-1}\left[R_{k}(\Delta t)-G_{k}(\Delta t)\right]^{2}}{\sum_{k=0}^{n-1}\left[G_{k}(\Delta t)\right]^{2}}}, \\
& =\frac{\sum_{k=0}^{n-1}\left[R_{i k}(\Delta t)-\overline{R_{i}}(\Delta t)\right]\left[G_{j k}(\Delta t)-\overline{G_{j}}(\Delta t)\right]}{\sqrt{\sum_{k=0}^{n-1}\left[R_{i k}(\Delta t)-\overline{R_{i}}(\Delta t)\right]^{2}} \sqrt{\sum_{k=0}^{n-1}\left[G_{j k}(\Delta t)-\overline{G_{j}}(\Delta t)\right]^{2}}},
\end{aligned}
$$

where $n$ is the number of $R$ and $G$ pairs at a given temporal integration $\Delta t$ and the overbar indicates the temporal average.
3.3. Spatial Correlation and Variability of the Rain Fields. Rain gauges are widely used to measure rainfall amounts due to many advantages, including easy installation, mobility, low price, and ease of data processing. The rain gauge data is used as a reference for the ground rainfall amount for the evaluation of rain retrieval algorithms, adjustment of other instruments, data assimilation, and other hydrological applications. However, it is affected by instrumental errors and representativeness errors due to the variability of rain fields.

In a $\mathrm{TB}$ rain gauge, the instrumental errors are due to improper calibration, the time delay of the tips, leakage due to its measuring principle, and so forth. This error is explored in the Appendix.

The representativeness errors are subdivided into spatial and temporal representativeness. They are mainly caused by having a small sampling area and a limited sampling time due to the gauge measuring principle. The actual rain fields vary with different spatiotemporal scales that are not equivalent to the spatial and temporal resolution of the rain gauge. Therefore, the rain gauge data represent the actual rain fields in a very limited manner.

These errors should be considered and minimized prior to using rain gauge data as ground truth. Furthermore, the degree of these errors has to be understood quantitatively, since there can be other error sources in various applications. In this section, the spatial and temporal variability of the rain fields are investigated using the rain data collected by the ten rain gauges for the month of July 2010 at Muan, Korea.

First, the Spearman correlation coefficient $r_{i j}(\Delta t)$ between a pair of $G$ values from the $i$ th and $j$ th individual rain gauge with integration time $\Delta t$ was calculated from the following equation to obtain the Spearman correlation coefficient of the rain fields:

$$
\begin{aligned}
& r_{i j}(\Delta t) \\
& =\frac{\sum_{k=0}^{n-1}\left[G_{i k}(\Delta t)-\overline{G_{i}}(\Delta t)\right]\left[G_{j k}(\Delta t)-\overline{G_{j}}(\Delta t)\right]}{\sqrt{\sum_{k=0}^{n-1}\left[G_{i k}(\Delta t)-\overline{G_{i}}(\Delta t)\right]^{2}} \sqrt{\sum_{k=0}^{n-1}\left[G_{j k}(\Delta t)-\overline{G_{j}}(\Delta t)\right]^{2}}},
\end{aligned}
$$

where $n$ is the number of gauge data pairs at given $\Delta t$ and the overbar indicates the temporal average of the rainfall rate. It was derived with $\Delta t$ to research the spatial and temporal scale of the variation for the rain field.

In addition, the effect of the natural variability of the rain fields within two different areas $\left(0.38 \mathrm{~km}^{2}\right.$ and $\left.6 \mathrm{~km}^{2}\right)$ was explored by analyzing the bias and random error between the spatially averaged rainfall rate $\langle G\rangle$ and $G$ from the individual 


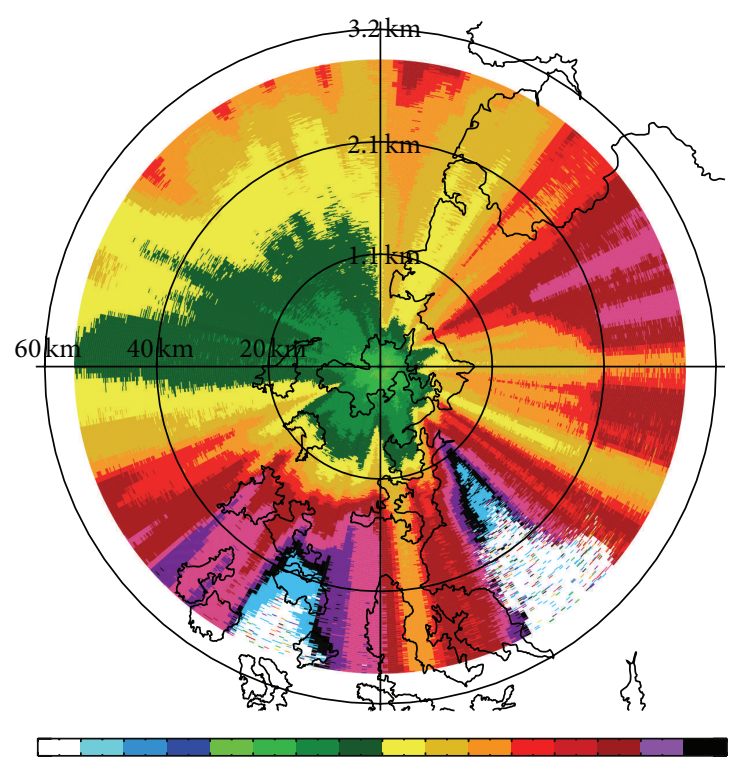

$\begin{array}{llllllllllll}-180 & 0 & 10 & 20 & 30 & 40 & 50 & 60 & 70 & 80 & 90 & 100120140160180\end{array}$

(a)

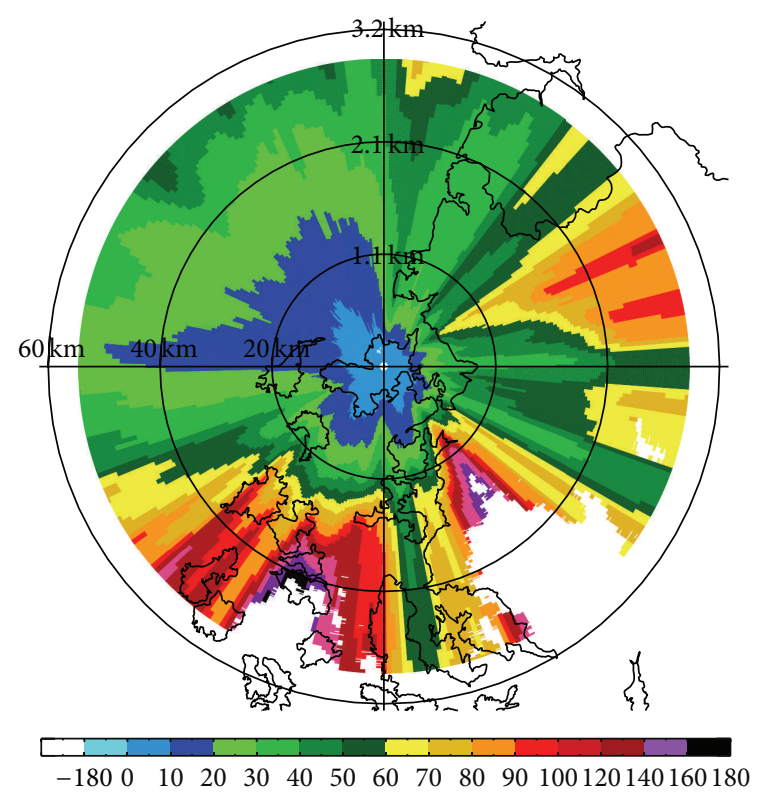

(b)

FIGURE 5: PPIs of measured (a) and filtered (b) $\Psi_{\text {DP }}$ of the NIMS-XPOL at 2101 UTC, July 10, 2010.

gauge. The NB and NSD of $G_{i}$ with $\langle G\rangle$ were calculated as follows:

$$
\begin{aligned}
\mathrm{NB}(i) & =\frac{\left(\sum_{k=0}^{n-1}\left[G_{i k}(\Delta t)-\left\langle G_{k}(\Delta t)\right\rangle\right]\right) / n}{\overline{\langle G(\Delta t)\rangle}}, \\
\operatorname{NSD}(i) & =\frac{(1 / n) \sqrt{\left(\sum_{k=0}^{n-1}\left[G_{i k}(\Delta t)-\left\langle G_{k}(\Delta t)\right\rangle\right]^{2}\right)}}{\overline{\langle G(\Delta t)\rangle}},
\end{aligned}
$$

where $i$ indicates the $i$ th gauge and the overbar indicates the temporal average.

This analysis provided a reasonable spatial average and temporal accumulation resolution for the calculation of more accurate and realistic rainfall amounts from the gauge data and a quantitative guideline regarding the errors in rain estimation due to the variability of the rain fields.

\section{Results}

4.1. Attenuation Correction of Reflectivity and Differential Reflectivity. The attenuation correction algorithm in Section 3.1 was applied to the NIMS-XPOL radar data. $\Phi_{\mathrm{DP}}$ was estimated by eliminating $\delta$ and the observational noise from measured $\Psi_{\mathrm{DP}}$ using an iterative FIR filter. The offset of $\Phi_{\mathrm{DP}}$ was then adjusted. Figure 5 shows the PPIs of measured $\Psi_{\mathrm{DP}}$ and filtered $\Phi_{\mathrm{DP}}$. After applying the FIR filter, the small scale variation due to $\delta$ and observational noise in measured $\Psi_{\mathrm{DP}}$ was reduced, and filtered $\Psi_{\mathrm{DP}}$ (estimated $\left.\Phi_{\mathrm{DP}}\right)$ monotonically increased with an increase in range. The maximum value of estimated $\Phi_{\mathrm{DP}}$ reached to $140^{\circ}$. In addition, estimated $\Phi_{\mathrm{DP}}$ at the azimuth angles of $150^{\circ}$ and $200^{\circ}$ sharply increased with the loss of signal beyond these sharp gradient areas. This reflected that strong convective cells existed in these directions and that these cells caused the severe signal attenuation. Estimated $\Phi_{\mathrm{DP}}$ values between $250^{\circ}$ and $360^{\circ}$ azimuth angle decreased after filtering since $\Phi_{D P}$ offsets were positive values in these directions. Figure 6 shows the range profile of measured and filtered $\Psi_{\mathrm{DP}}$ for estimation of $\Phi_{\mathrm{DP}}$ at $71^{\circ}, 160^{\circ}$, and $334^{\circ}$ azimuth angles. The unexpected large values near the radar were removed by the $\rho_{\mathrm{HV}}$ threshold (red line). The small fluctuation in measured $\Psi_{\mathrm{DP}}$ due to $\delta$ and the observational noise was effectively removed after filtering. The value of estimated $\Phi_{\mathrm{DP}}$ was adjusted to 0 by the offset (blue line).

Estimated $\Phi_{\mathrm{DP}}$ was used to calculate the path integrated $A_{H}$, and the measured $Z_{H}$ values were corrected as shown in Figure 7. Figure 7 (a) represents measured-attenuated $Z_{H}$ and relatively small values of $Z_{H}$ at far ranges. This may indicate that the $Z_{H}$ values at far ranges were affected by the strong attenuation due to strong convective cells near the radar. This spatial pattern of $Z_{H}$ was the typical feature of the attenuated radar signal due to the rain. After correcting the attenuation, the value of the $Z_{H}$ field became larger over the entire area, and the radially attenuated $Z_{H}$ was corrected by showing a typical rain cell pattern in $Z_{H}$ (Figure $7(\mathrm{~b})$ ). The largest difference between the uncorrected and the corrected $Z_{H}$ at $2101 \mathrm{UTC}$ was over $50 \mathrm{~dB}$. However, the white area behind the strong echoes was not detected as there was a complete loss of the signal power. These regions could not be corrected by this algorithm. The circle pattern of $Z_{H}$ fields within about a $4 \mathrm{~km}$ range from the NIMS-XPOL could not present the actual rain echoes due to the instrumental issues (the same was true for $\left.Z_{\mathrm{DR}}\right)$. These results are also presented in the range profiles in Figure 8.

Similarly, measured $Z_{\mathrm{DR}}$ were corrected with the path integrated $A_{\mathrm{DP}}$ derived from the path integrated $A_{H}$ using (4) (see Figure 9). Before applying attenuation correction, 


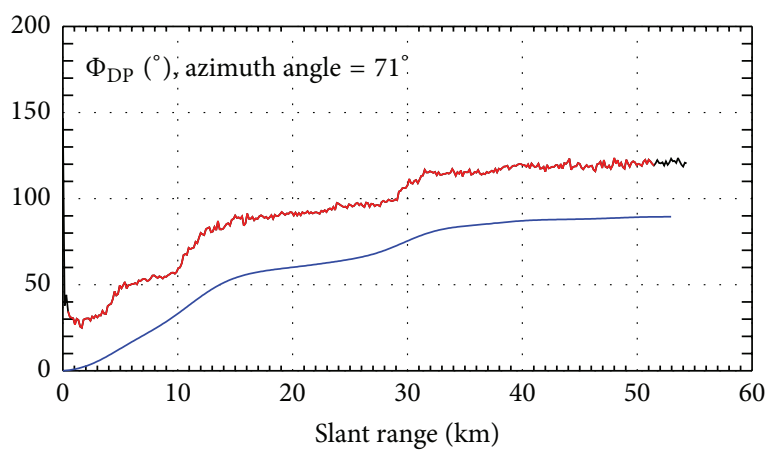

Measured data
_ Preprocessed data
Corrected data

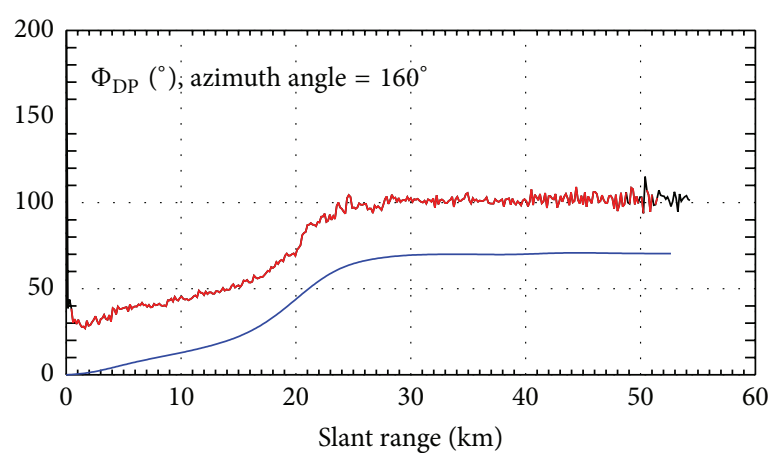

— Measured data

Preprocessed data

- Corrected data

(a)

(b)

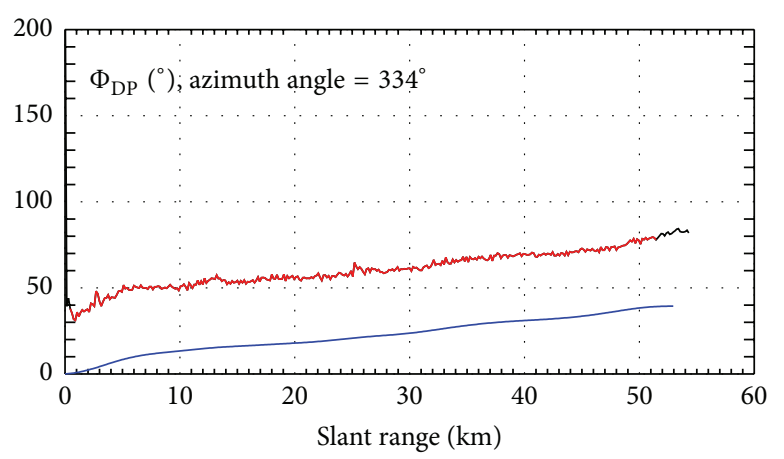

— Measured data

(c)

FIGURE 6: Range profiles of measured (black); $\rho_{\mathrm{HV}}$ threshold, isolated point removing (red); and FIR filter and offset adjusted (blue) $\Psi_{\mathrm{DP}}$ for estimation of $\Phi_{\mathrm{DP}}$ at $71^{\circ}$ (a), $160^{\circ}$ (b), and $334^{\circ}$ (c) azimuth angles of NIMS-XPOL for the case in Figure 5.

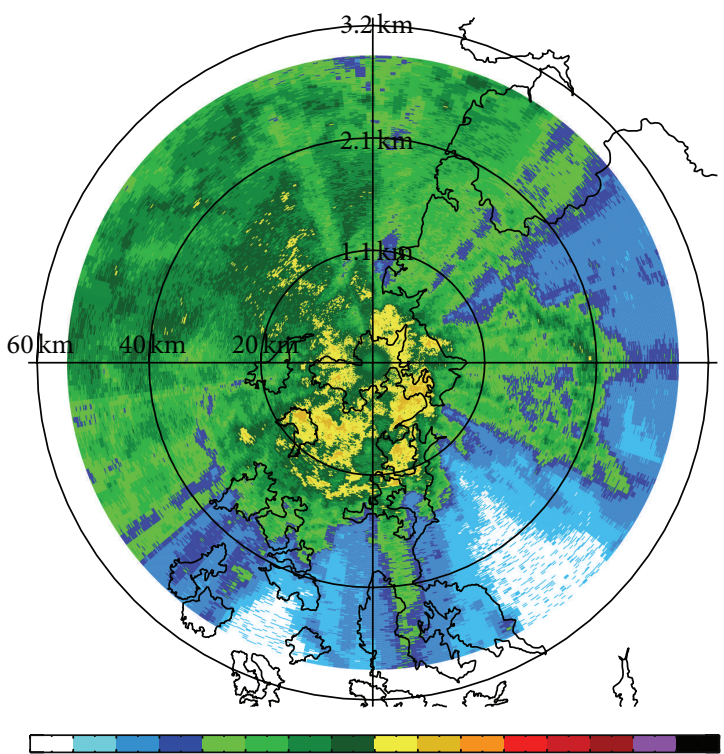

$\begin{array}{lllllllllllllll}-10 & 0 & 10 & 15 & 20 & 25 & 30 & 35 & 40 & 45 & 50 & 55 & 60 & 65 & 70\end{array}$

(a)

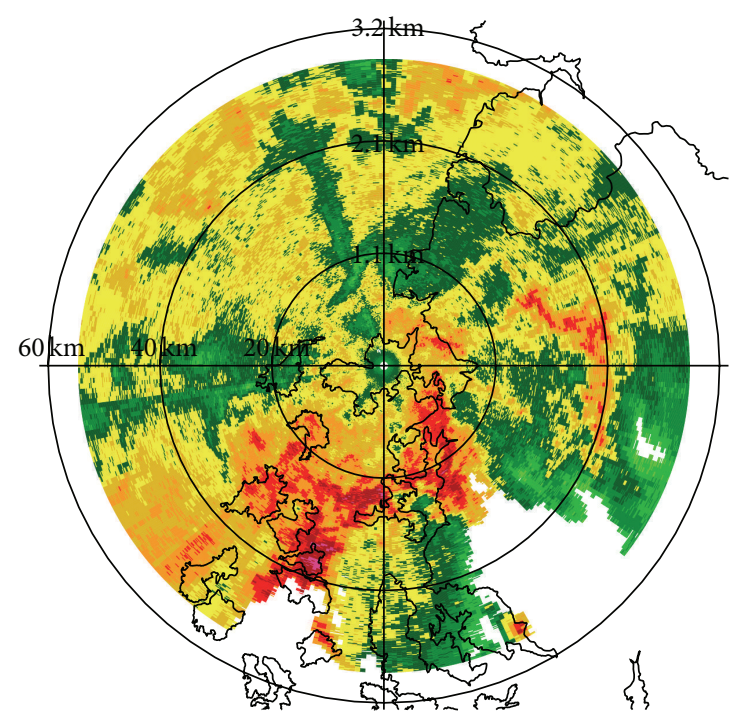

$\begin{array}{lllllllllllllll}-10 & 0 & 10 & 15 & 20 & 25 & 30 & 35 & 40 & 45 & 50 & 55 & 60 & 65 & 70\end{array}$

(b)

Figure 7: PPIs of measured (a) and attenuation corrected (b) $Z_{H}$ of the NIMS-XPOL for the case in Figure 5. 


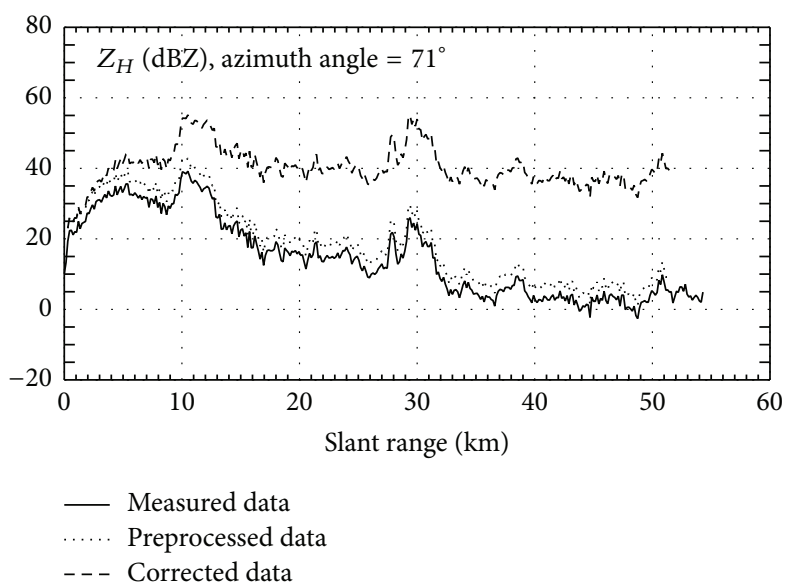

(a)

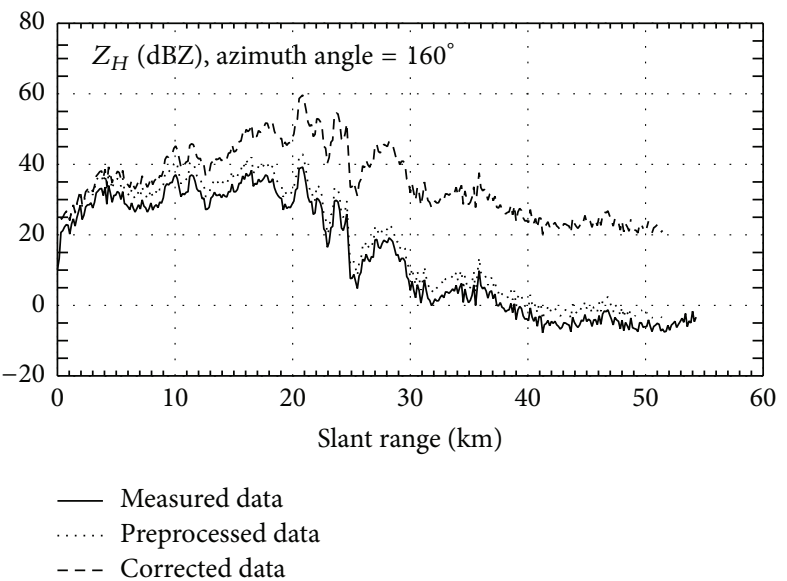

(b)

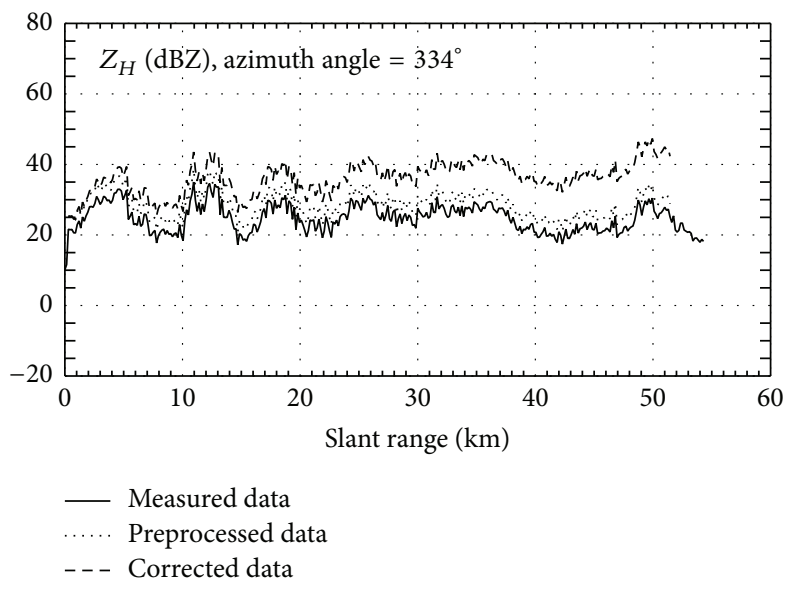

(c)

Figure 8: Range profiles of measured (line); calibration bias, $\rho_{\mathrm{HV}}$ threshold, and isolated point removing (dot); and attenuation corrected (dash) $Z_{H}$ at $71^{\circ}$ (a), $160^{\circ}$ (b), and $334^{\circ}$ (c) azimuth angles of NIMS-XPOL for the case in Figure 5.

the attenuation signature in $Z_{\mathrm{DR}}$ was determined. Ideally, the $Z_{\mathrm{DR}}$ value for rain should be positive since rain drops are oblate due to aerodynamic force. However, the measured $Z_{\mathrm{DR}}$ field in Figure 9 showed a negative value over wide areas. After correcting the attenuation, the $Z_{\mathrm{DR}}$ field was larger than $0 \mathrm{~dB}$ and showed a realistic rain pattern. This is also presented in the range profile of Figure 10. The largest difference of $Z_{\mathrm{DR}}$ between before and after attenuation correction at 2101 UTC was about $8 \mathrm{~dB}$. The $Z_{\mathrm{DR}}$ values around the $220^{\circ}$ azimuth angle beyond $40 \mathrm{~km}$ were the largest. They did not match with the area of the largest $Z_{\mathrm{DR}}$ values (around the $210^{\circ}$ azimuth angle with a range of $20 \mathrm{~km}$ and $40 \mathrm{~km}$ ). This was an unexpected result because $Z_{\mathrm{DR}}$ is proportional to $Z_{H}$ in theory. This mismatch between $Z_{H}$ and $Z_{\mathrm{DR}}$ at far range may be due to contamination due to beam broadening and accumulated errors due to uncertainty in the attenuation correction with different ranges.

Figures 11 and 12 show the time series of $Z_{H}$ and $Z_{\mathrm{DR}}$ at the ten gauge sites before and after applying the attenuation correction. The differences between uncorrected and corrected values existed after 1800 UTC and were at a maximum around 2100 UTC. This attenuation correction was evaluated through comparison with the theoretical values of $Z_{H}$ and $Z_{\mathrm{DR}}$. In Figure 13 , the uncorrected $Z_{H^{-}} Z_{\mathrm{DR}}$ scatter plots are apart from the theoretical $Z_{H}-Z_{\mathrm{DR}}$ values [23]. After attenuation correction, the $Z_{H}-Z_{\mathrm{DR}}$ scatter plots were close to the calculated values. This indicated that $Z_{H}$ and $Z_{\mathrm{DR}}$ over the gauge sites were corrected with reliable values.

4.2. Variability of the Rain Fields. The Spearman correlation coefficient of the rainfall rate from the 10 spatially distributed rain gauges was calculated with accumulation time and separation distance (Figure 14). The overall Spearman correlation coefficient decreased with increasing separation distance at all accumulation times. This tendency was similar to the result from Habib and Krajewski [24]. However, the correlation value was higher in this study. Note that the gauge tip resolution in Habib and Krajewski [24] was $0.254 \mathrm{~mm}$, while it was $0.2 \mathrm{~mm}$ in this study. In addition, the rainfall rates from the gauge data used in this study mainly consisted of moderate rainfall rates, while Habib and Krajewski [24] used data containing heavy rainfall rates.

For accumulation times of less than $10 \mathrm{~min}$, the correlation at the same distance was dramatically increased with 


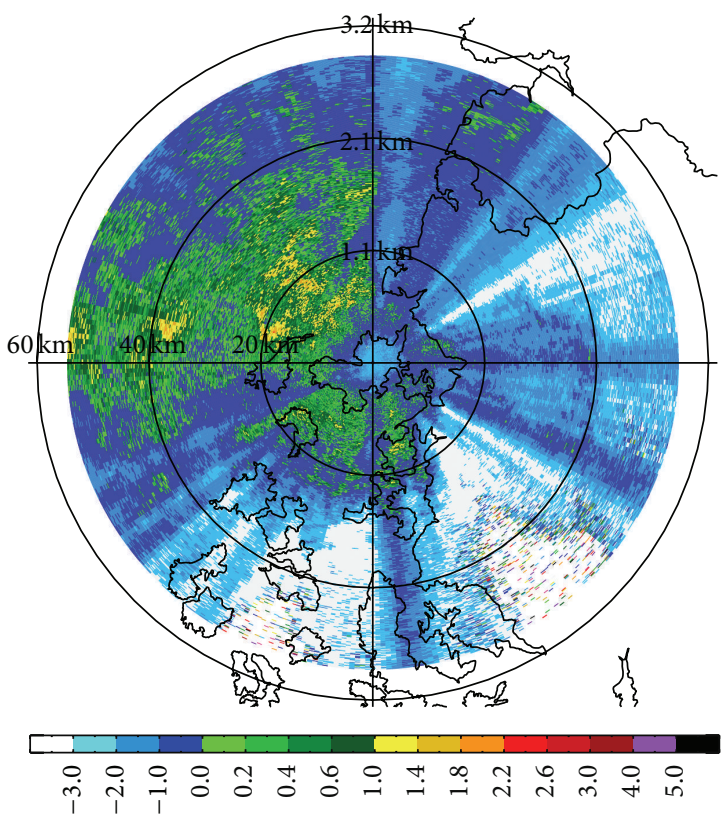

(a)

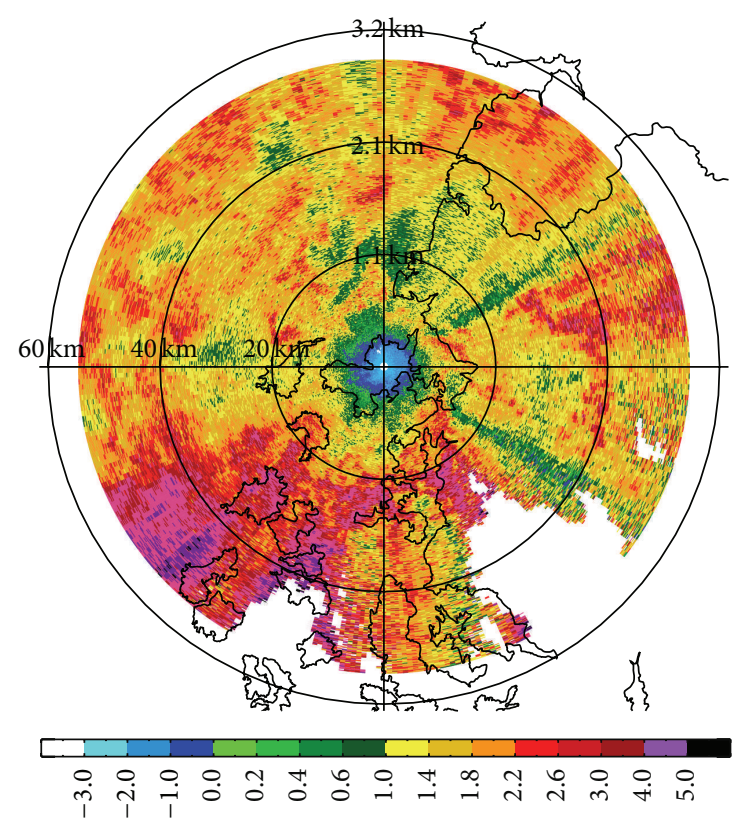

(b)

FIGURE 9: PPIs of measured (a) and attenuation corrected (b) $Z_{\mathrm{DR}}$ of NIMS-XPOL for the case in Figure 5.

increasing accumulation time, and the slope of the correlation function was steep. This was due to the reduction of the instrumental errors of the gauge data by time accumulation. This indicated that rainfall accumulated for less than $10 \mathrm{~min}$ from single gauge data cannot represent the rainfall over its surrounding area due to instrumental errors. For accumulation times longer than $10 \mathrm{~min}$, the slope became less steep. This reflected the remaining variability of the rain field. In addition, the accumulated rainfall rate of about 10 min was suitable for minimizing the instrumental uncertainty while preserving the variation in the rain field. The correlation reached about 0.98 at $0.5 \mathrm{~km}$ in $10 \mathrm{~min}$ of accumulation, and this approached 0.98 at $1.0 \mathrm{~km}$ at $60 \mathrm{~min}$ accumulation. Therefore, a single rain gauge mostly represented the rainfall rate within $0.5 \mathrm{~km}$ and $1.0 \mathrm{~km}$ with $10 \mathrm{~min}$ and $60 \mathrm{~min}$ accumulation, respectively.

The NB between an areal averaged rainfall rate $\langle G\rangle$ and a single gauge rainfall rate $G$ is shown with accumulation time in Figures 15(a) and 16(a). Where the average area was $0.38 \mathrm{~km}^{2}$ (corresponding to 9 pixels of NIMS-XPOL radar at $16 \mathrm{~km}$ range), the $\mathrm{NB}$ reached a $6-8 \%$ maximum. Where the averaged area is $6 \mathrm{~km}^{2}$ (corresponding to the coverage for all of the gauges), the NB reached about a $10 \%$ maximum. Furthermore, the NB hardly changed with accumulation time. Note that this statistic was derived after removing instrumental bias. This indicated that the rainfall rate from a single gauge was biased due to the spatial variability of the rain fields, and this bias was maintained with accumulation time.

The NSD of a single gauge for a mean area of $0.38 \mathrm{~km}^{2}$ was over $40 \%$, and it reached about $70-90 \%$ for a mean area of $6 \mathrm{~km}^{2}$ at an accumulation time of $1 \mathrm{~min}$ (see Figures 15(b) and 16(b)). This statistic included instrumental errors (about
$40-60 \%$ at $16 \mathrm{~mm} \mathrm{~h}^{-1}$ and $60-80 \%$ at $10 \mathrm{~mm} \mathrm{~h}^{-1}$ as shown in the Appendix) as well as the spatial variability of the rain fields. This indicated that the variance between the point and area values from the gauge data at short accumulation times was similar to the errors due to the instrumental uncertainty of the rain gauge. The NSD in $60 \mathrm{~min}$ accumulation decreased to over $10 \%$ and about $15-45 \%$ with a mean area of $0.38 \mathrm{~km}^{2}$ and $6 \mathrm{~km}^{2}$, respectively, including the NSD of $6-10 \%$ due to instrumental uncertainty. This indicated that the rainfall rate from single gauges may differ significantly from the actual rainfall rate due to the variability of the rain fields and the instrumental uncertainty in short accumulation times.

4.3. Verification of Rainfall Retrieval. The rainfall rate from the NIMS-XPOL radar measurements was retrieved with two rainfall rate estimators: $R\left(Z_{H}\right)$ and $R\left(Z_{H}, Z_{\mathrm{DR}}\right)$. The estimated rainfall rate was verified through comparison with the rainfall rate $(G)$ from the rain gauge data. These two estimators were applied before and after the attenuation correction. First, $R\left(0.38 \mathrm{~km}^{2}\right)$ was compared with $R\left(0.07 \mathrm{~km}^{2}\right)$ at $10 \mathrm{~min}$ accumulation (Figure 17$)$. Using $R\left(Z_{H}\right)$, the $\mathrm{NB}$, NSD, rmse, and r_rmse without the attenuation correction were significantly large at $70 \%, 127 \%, 12.7(\mathrm{~mm} / \mathrm{hr})$, and $78 \%$, respectively. However, they were reduced to $-1 \%$, $52 \%, 5.21(\mathrm{~mm} / \mathrm{hr})$, and $32 \%$, respectively, after applying the attenuation correction. Using $R\left(Z_{H}, Z_{\mathrm{DR}}\right)$, the NB was just $3 \%$, NSD was $49 \%$, rmse was $4.96(\mathrm{~mm} / \mathrm{hr})$, and r_rmse was $31 \%$ before applying attenuation correction. This was similar to the result from $R\left(Z_{H}\right)$ after attenuation correction. However, there was no significant change in $R\left(Z_{H}, Z_{\mathrm{DR}}\right)$ with attenuation correction. This means that $R\left(Z_{H}, Z_{\mathrm{DR}}\right)$ was less sensitive to rain attenuation than was $R\left(Z_{H}\right)$, because $Z_{H}$ is proportional to $R$, and $Z_{\mathrm{DR}}$ is inversely proportional to $R$ 


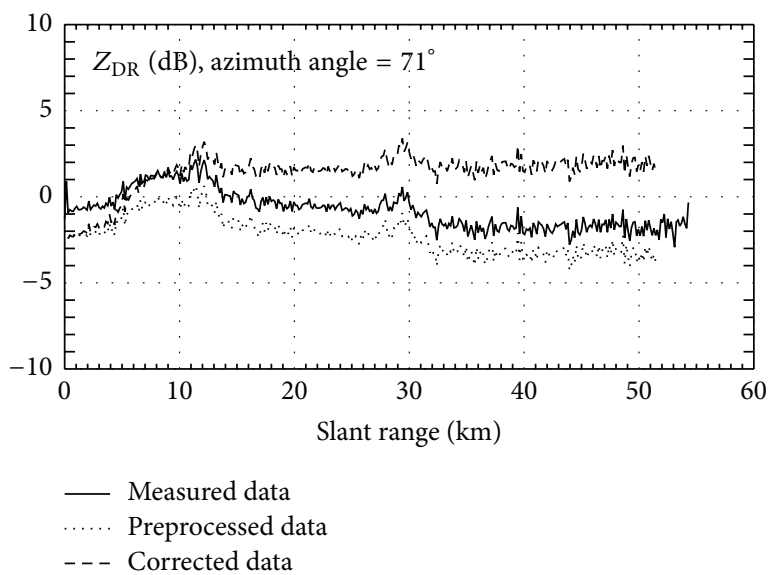

(a)

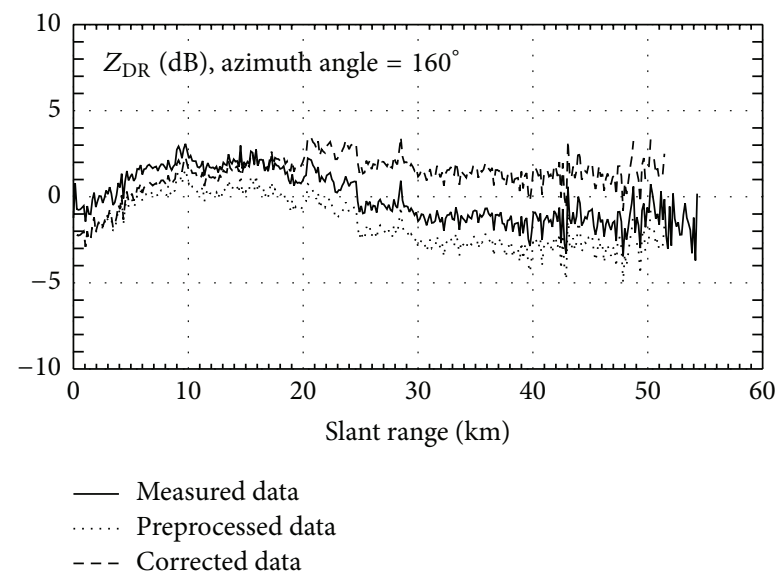

(b)

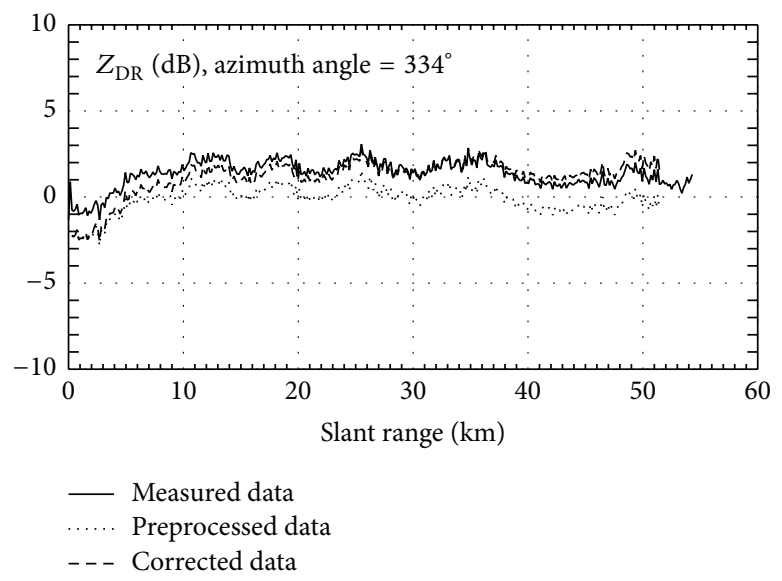

(c)

FIGURE 10: Range profiles of measured (line); calibration bias, $\rho_{\mathrm{HV}}$ threshold, and isolated point removing (dot); and attenuation corrected (dash) $Z_{\mathrm{DR}}$ at $71^{\circ}$ (a), $160^{\circ}$ (b), and $334^{\circ}$ (c) azimuth angles of NIMS-XPOL for the case in Figure 5.

in this rain estimator (see Table 3). Furthermore, comparing the analysis of variance results between areal $\left(0.38 \mathrm{~km}^{2}\right)$ and point $\left(0.07 \mathrm{~m}^{2}\right)$ values from the gauge data (Section 4.2 ), half of the errors after attenuation correction were produced by the small scale variability of the rain fields and the instrumental uncertainty of the rain gauge.

A similar comparison is shown in Figure 18 for a $60 \mathrm{~min}$ accumulation. Using $R\left(Z_{H}\right)$, the NB, NSD, rmse, and r_rmse were decreased from $-65 \%, 86 \%, 7.1(\mathrm{~mm} / \mathrm{hr})$, and $70 \%$ to $-5 \%, 34 \%, 2.8(\mathrm{~mm} / \mathrm{hr})$, and $28 \%$ by the attenuation correction, respectively. Using $R\left(Z_{H}, Z_{\mathrm{DR}}\right)$, the $\mathrm{NB}, \mathrm{NSD}$, rmse, and r_rmse were only slightly decreased after the attenuation correction. However, the NSD, rmse, and r_rmse were reduced when compared at $10 \mathrm{~min}$ accumulation. In the same accumulation time, the errors in the gauge data reached to over $15 \%$.

This comparison was affected by different sampling areas of the gauges and the radar. Therefore, the areal average values were compared (Figure 19). Using $R\left(Z_{H}\right)$ with the areal averaged radar measurements, the NB was reduced from $-69 \%$ to $7 \%$, NSD was reduced from $122 \%$ to $42 \%$, rmse was reduced from $3.9(\mathrm{~mm} / \mathrm{hr})$ to $1.3(\mathrm{~mm} / \mathrm{hr})$, and r_rmse was reduced from $77 \%$ to $26 \%$ at an accumulation time of $10 \mathrm{~min}$. Using $R\left(Z_{H}, Z_{\mathrm{DR}}\right)$, the $\mathrm{NB}, \mathrm{NSD}$, rmse, and r_rmse were decreased from $-24 \%, 67 \%, 2.1(\mathrm{~mm} / \mathrm{hr})$, and $42 \%$ to $5 \%$, $39 \%, 1.2(\mathrm{~mm} / \mathrm{hr})$, and $24 \%$, respectively.

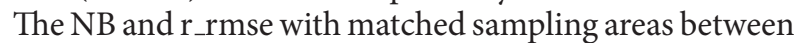
the gauge and the radar are shown in Figures 20 and 21. The reduction of $\mathrm{NB}$ due to temporal accumulation was small in both of the rain estimators. The NB was reduced to less than $7 \%$ by attenuation correction for all accumulation times with both $R\left(Z_{H}\right)$ and $R\left(Z_{H}, Z_{\mathrm{DR}}\right)$. The attenuation correction effect was significantly greater in $R\left(Z_{H}\right)$. Similarly, the r_rmse was reduced significantly in $R\left(Z_{H}\right)$ by attenuation correction (from $68 \%$ to $25 \%$ at a $60 \mathrm{~min}$ accumulation). The reduction of the $r_{-}$rmse due to temporal accumulation was larger in $R\left(Z_{H}, Z_{\mathrm{DR}}\right)$ because the significant observational noise of $Z_{\mathrm{DR}}$ was smoothed. The r.rmse was decreased from $18 \%$ to $15 \%$ in $R\left(Z_{H}, Z_{\mathrm{DR}}\right)$ at a $60 \mathrm{~min}$ accumulation time after attenuation correction.

\section{Conclusions}

In this study, an attenuation correction algorithm based on $\Phi_{\mathrm{DP}}$ was developed to improve the accuracy of the rainfall 

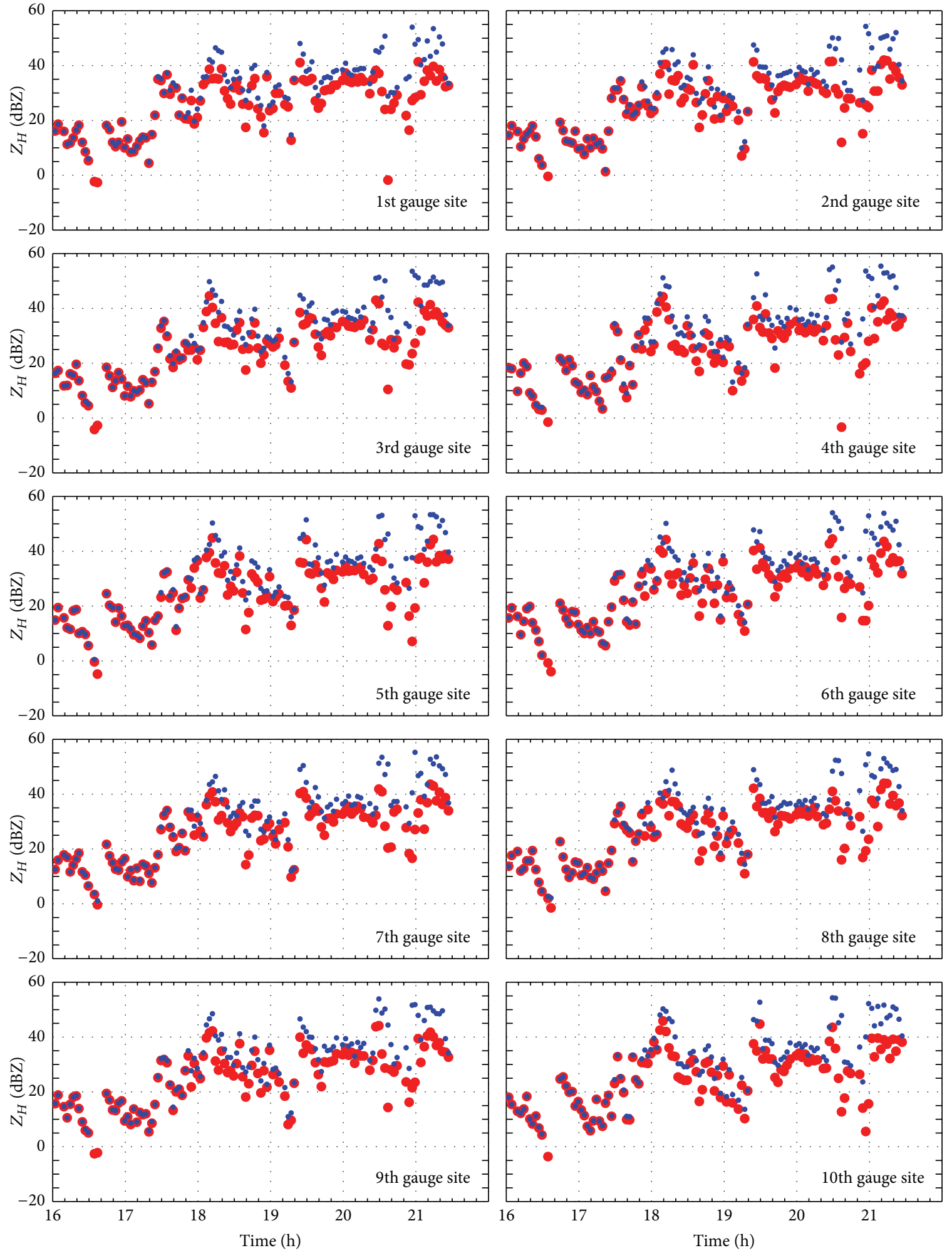

- Uncorrected

- Uncorrected

- Corrected

- Corrected

FIGURE 11: Time series of measured (red circle) and attenuation corrected (blue circle) $Z_{H}$ at the 10 rain gauge sites. 

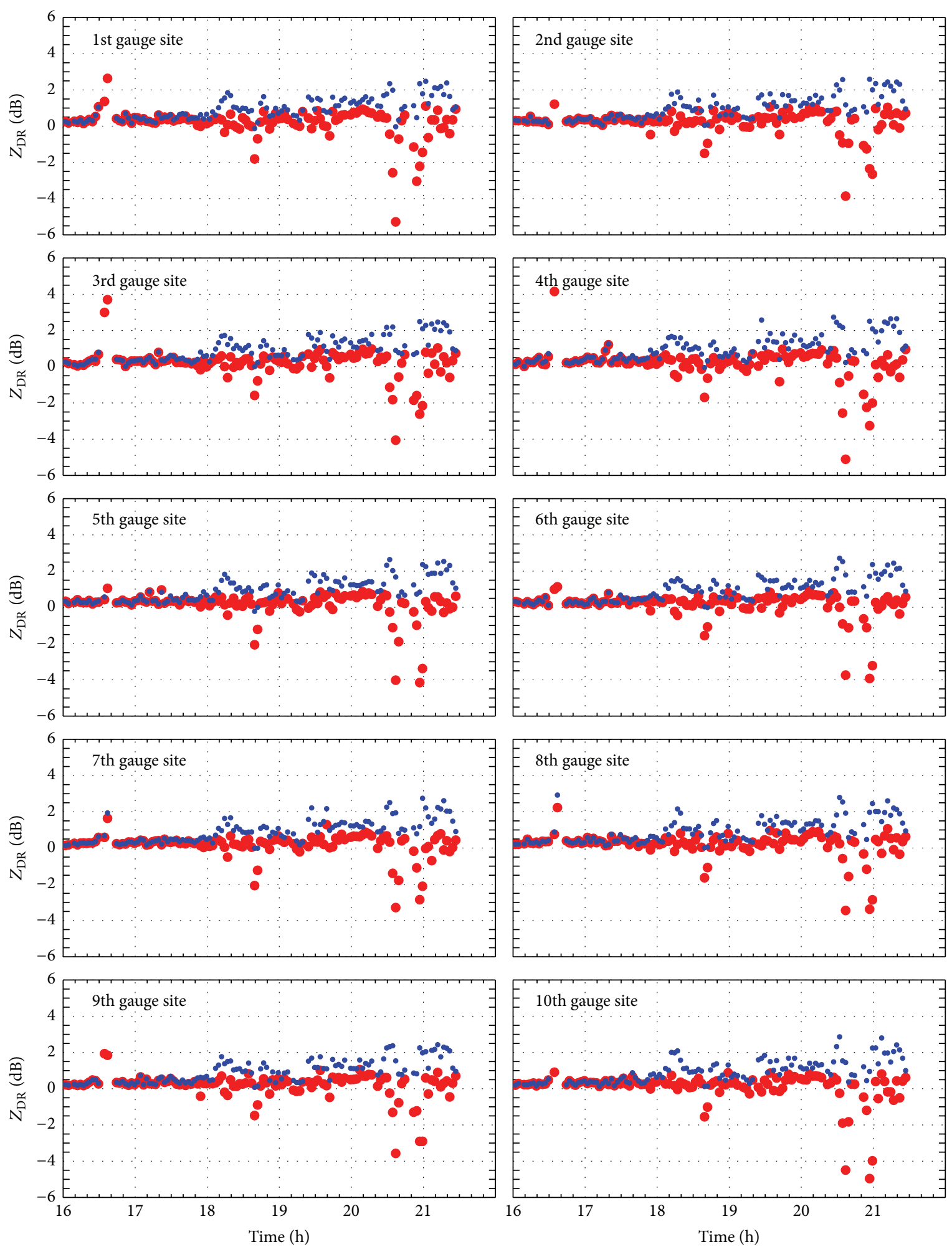

- Uncorrected

- Uncorrected

- Corrected

- Corrected

FIGURE 12: Time series of measured (red circle) and attenuation corrected (blue circle) $Z_{\mathrm{DR}}$ at the 10 rain gauge sites. 


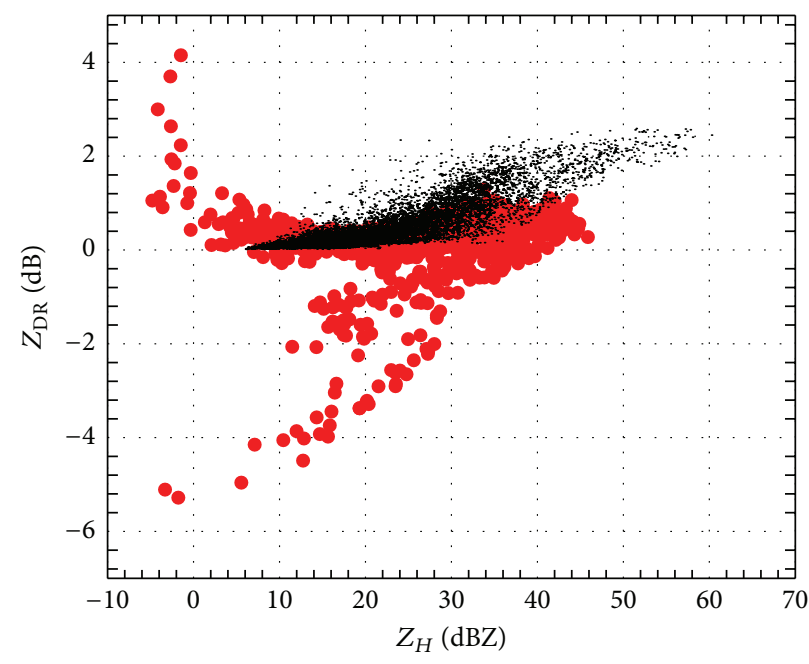

- Uncorrected

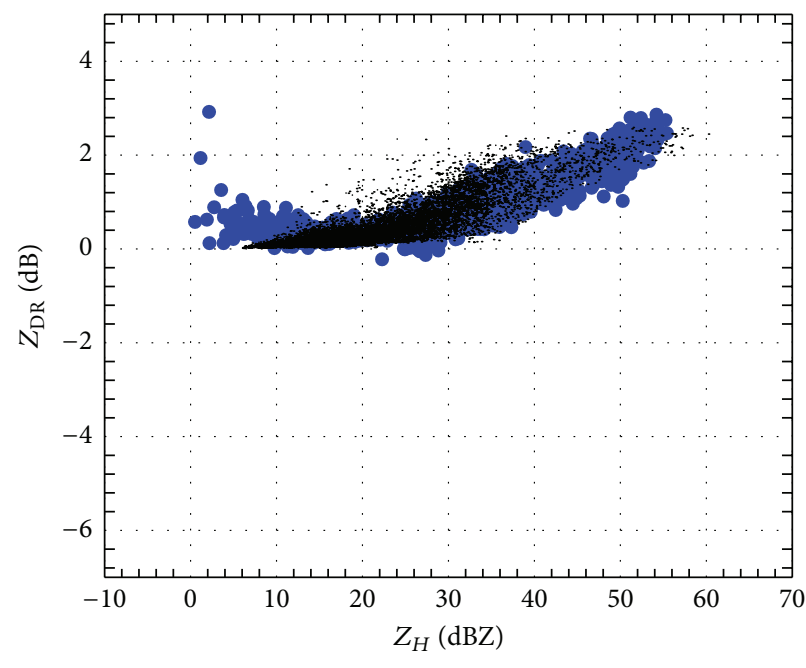

- Corrected

(b)

FIGURE 13: Scatter plots of $Z_{H}$ and $Z_{\mathrm{DR}}$ before (a) and after (b) attenuation correction at the 10 rain gauge sites. DSD observation results (dot [21]).
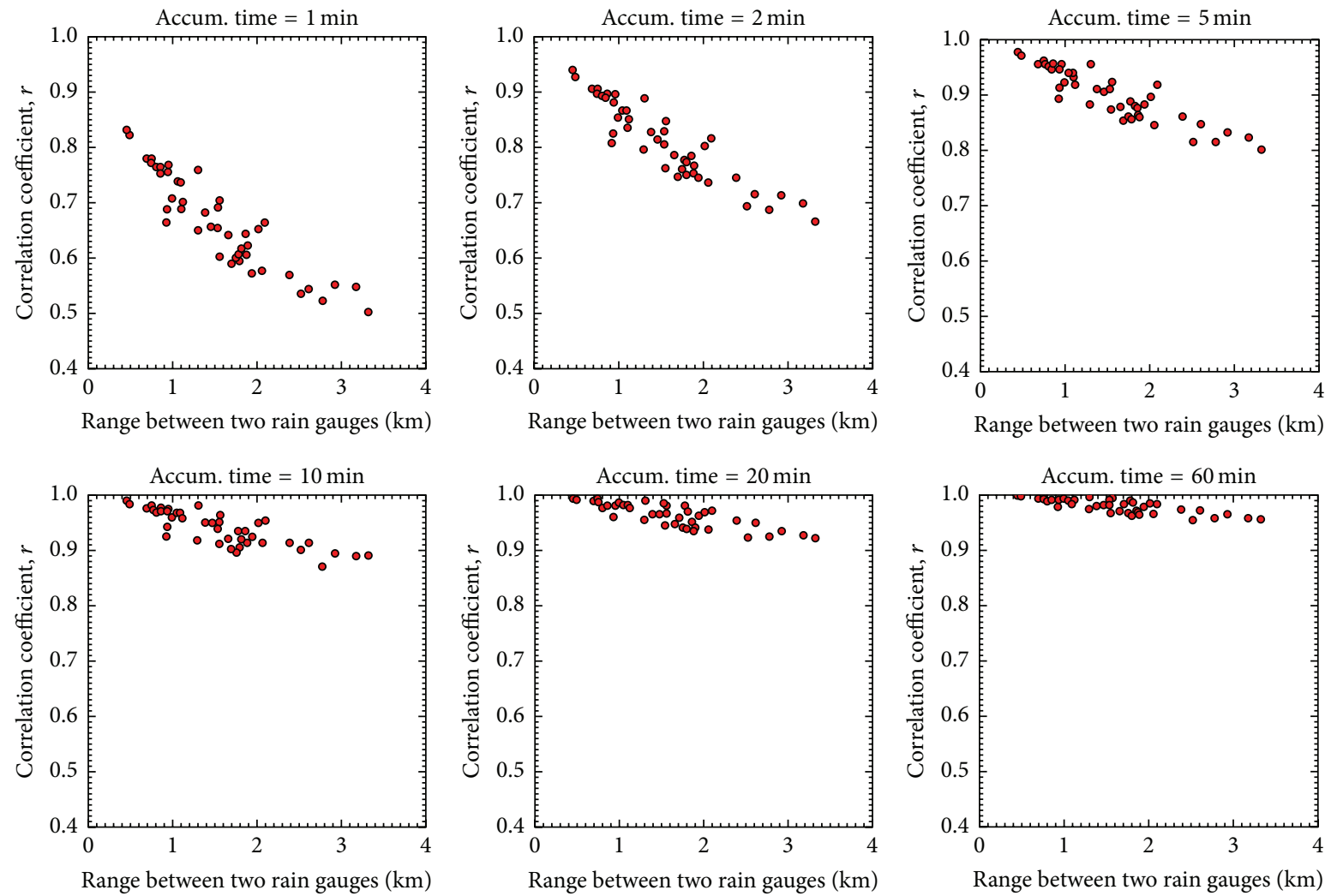

FIGURE 14: The Spearman correlation coefficient $r$ between data from two rain gauges at different accumulation times.

estimation using X-band radar. This algorithm was evaluated with radar measurements from NIMS-XPOL. However, measured $\Psi_{\mathrm{DP}}$ contained $\delta$ and observation noise as well as $\Phi_{\mathrm{DP}}$. Furthermore, the $\Psi_{\mathrm{DP}}$ offset varied with azimuth angles and decreased near the radar when rain cells were above the radar. In this study, $\Phi_{\mathrm{DP}}$ was estimated by an iterative filtering technique and by adjusting with an offset determined as the minimum value of $\Phi_{\mathrm{DP}}$ within $3 \mathrm{~km}$ of the radar. As a result, estimated $\Phi_{\mathrm{DP}}$ monotonically increased. The path integrated value of $A_{H}$ and $A_{\mathrm{DP}}$ was calculated from 


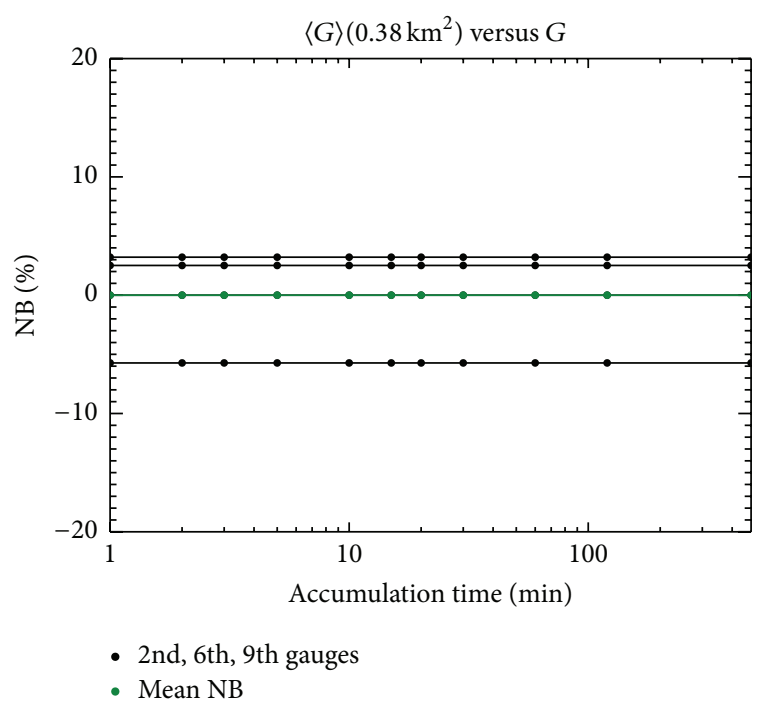

(a) Normalized bias

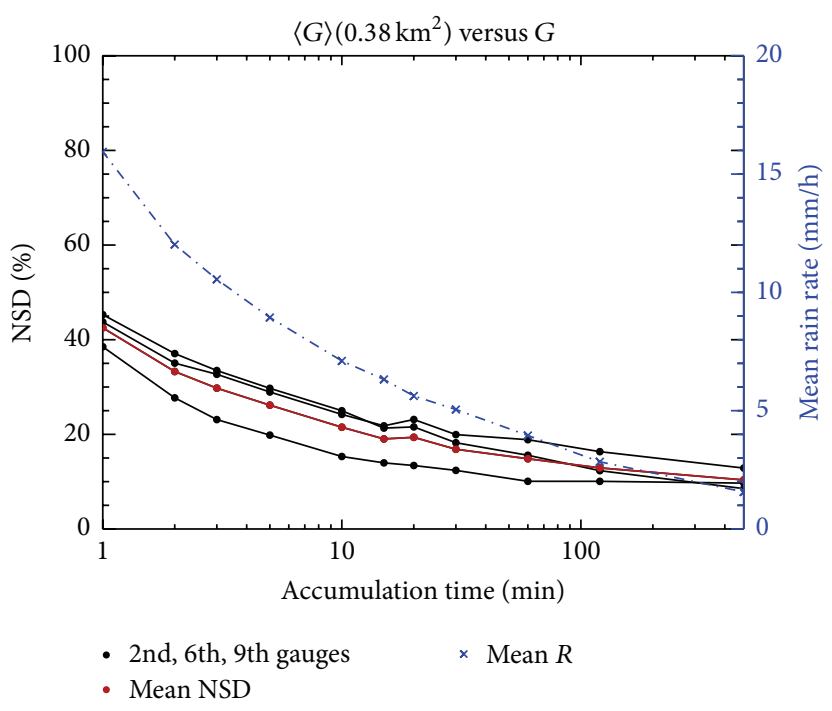

(b) Normalized standard deviation

Figure 15: (a) The NB and (b) NSD between $\langle G\rangle\left(0.38 \mathrm{~km}^{2}\right)$ and $G$ from three rain gauges with accumulation time. $\overline{\langle G\rangle}$ is the temporally averaged rainfall rate of $\langle G\rangle$.

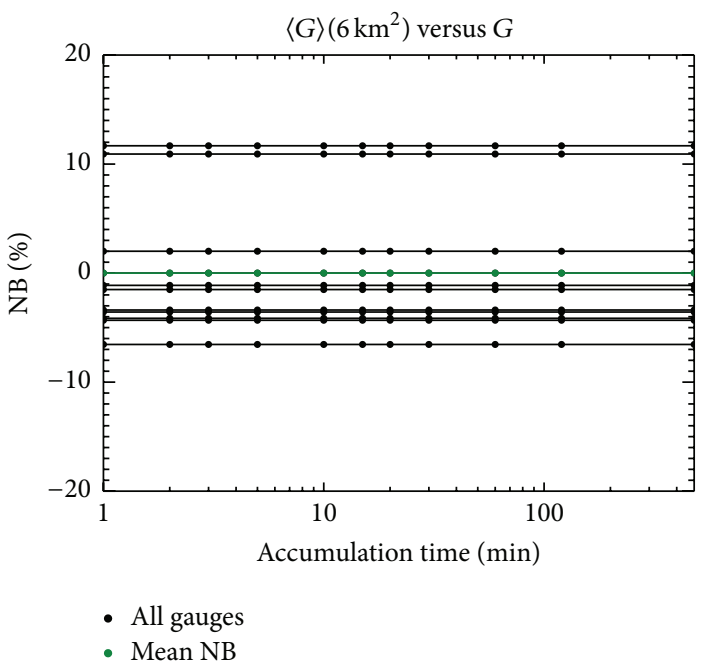

(a) Normalized bias

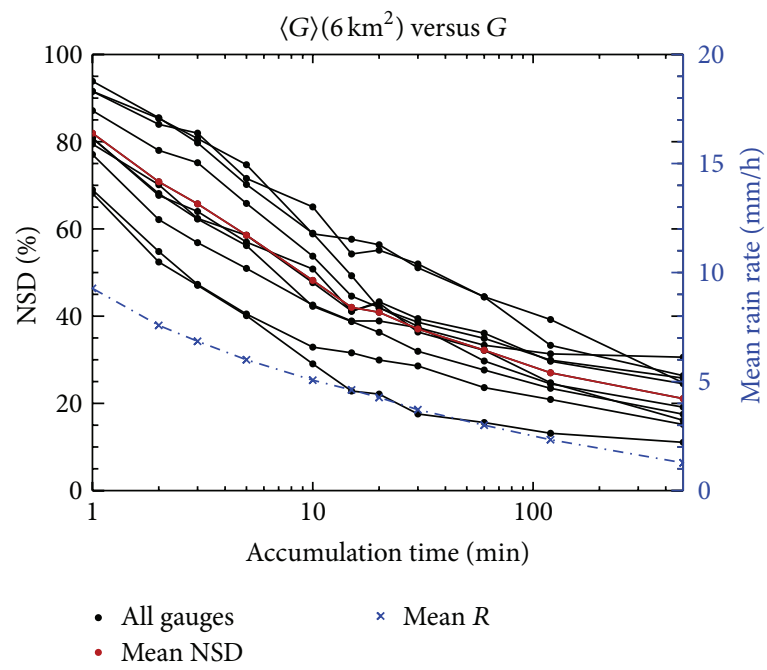

(b) Normalized standard deviation

FIGURE 16: (a) The NB and (b) NSD between $\langle G\rangle\left(6 \mathrm{~km}^{2}\right)$ and $G$ from 10 rain gauges with accumulation time. $\overline{\langle G\rangle}$ is the temporally averaged $\langle G\rangle$ with accumulation time.

estimated $\Phi_{\mathrm{DP}}$ using $A_{H^{-}} \Phi_{\mathrm{DP}}$ and $A_{\mathrm{DP}}-\Phi_{\mathrm{DP}}$ relationships derived from the DSDs data. Measured $Z_{H}$ and $Z_{\mathrm{DR}}$ were corrected with the calculated path integrated $A_{H}$ and $A_{\mathrm{DP}}$ by each gate. The attenuated signal patterns of $Z_{H}$ and $Z_{\mathrm{DR}}$ were restored to a typical rain echo pattern. However, the attenuation corrected $Z_{H}$ and $Z_{\mathrm{DR}}$ fields were not matched at distant ranges. This was likely because of contamination due to beam broadening and the accumulation of errors with increasing range. Comparing the $Z_{H^{-}} Z_{\mathrm{DR}}$ scatter plots over the 10 rain gauge sites with the results obtained from a scattering simulation with the DSD data, the attenuation corrected $Z_{H^{-}} Z_{\mathrm{DR}}$ scatter plots are in good agreement with the $Z_{H}-Z_{\mathrm{DR}}$ scatter plots from the DSDs.

The validation for the improvement of accuracy in the rainfall estimation through attenuation correction was performed by comparing with dense rain gauge network data. $R\left(Z_{H}\right)$ from the attenuated (observed) $Z_{H}$ produced a severe underestimation with an NB, NSD, rmse, and r_rmse of $70 \%, 127 \%, 12.7(\mathrm{~mm} / \mathrm{hr})$, and $78 \%$ at $10 \mathrm{~min}$ accumulation, respectively, while $R\left(Z_{H}\right)$ from the attenuation corrected $Z_{H}$ showed better agreement with the gauge measurements, with an NB, NSD, rmse, and r_rmse of $-1 \%, 52 \%, 5.21(\mathrm{~mm} / \mathrm{hr})$, 


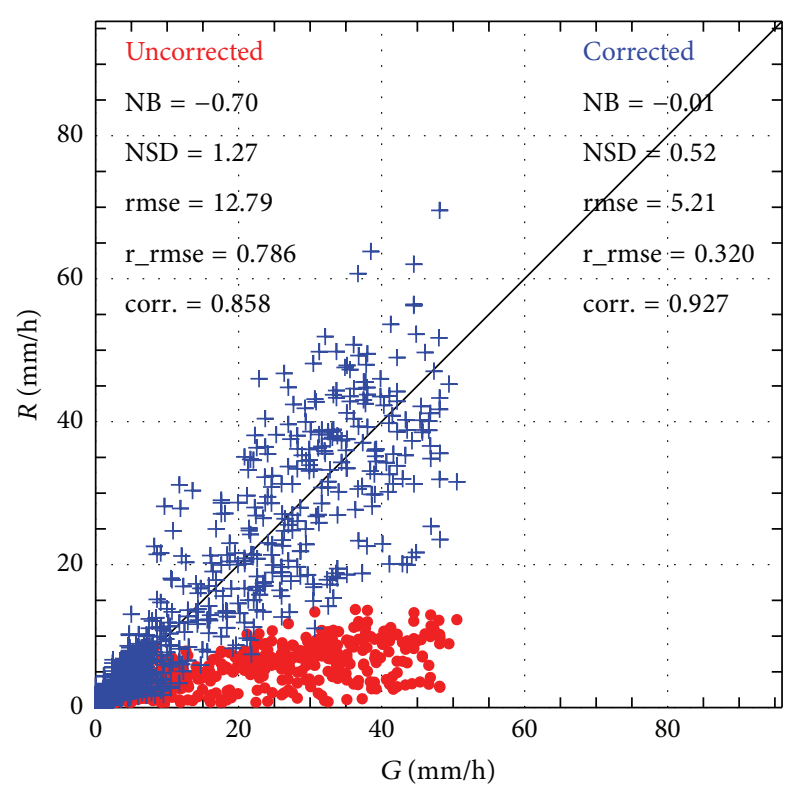

- Uncorrected

+ Corrected

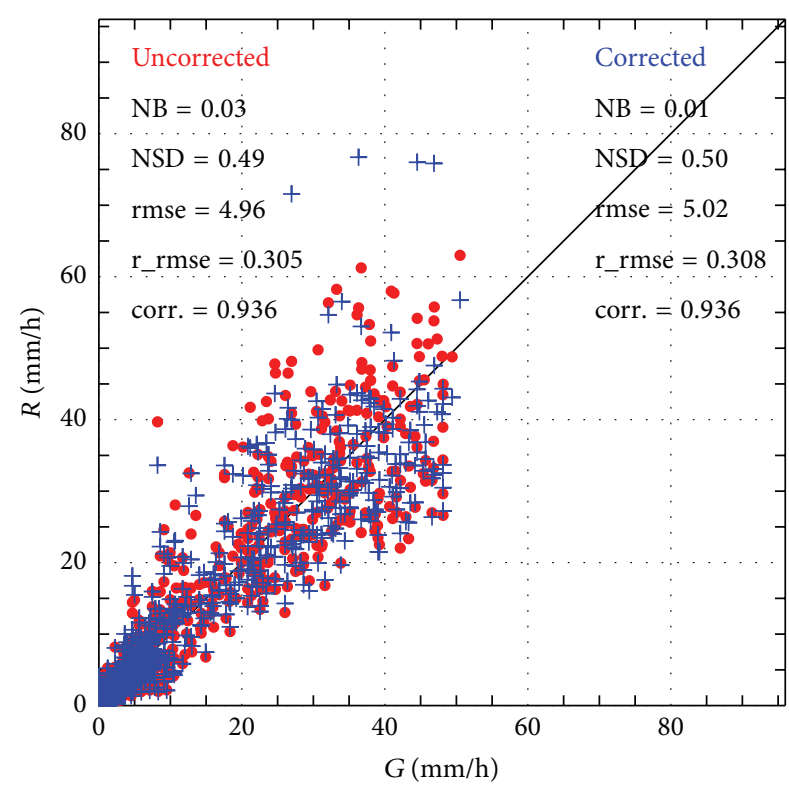

- Uncorrected

+ Corrected

(a) $R\left(Z_{H}\right)$

(b) $R\left(Z_{H}, Z_{\mathrm{DR}}\right)$

FIGURE 17: The scatter plots of $R\left(0.38 \mathrm{~km}^{2}, 10 \mathrm{~min}\right)$ versus $G\left(0.07 \mathrm{~m}^{2}, 10 \mathrm{~min}\right)$ (a) using $Z_{H}$ and (b) using $Z_{H}$ and $Z_{\mathrm{DR}}$.

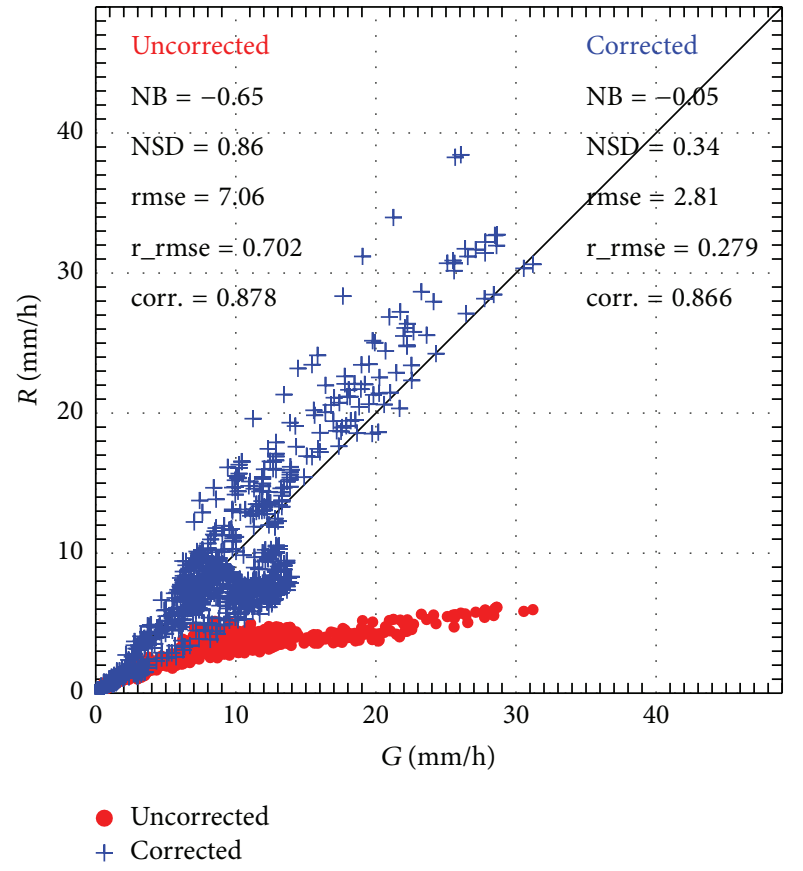

(a) $R\left(Z_{H}\right)$

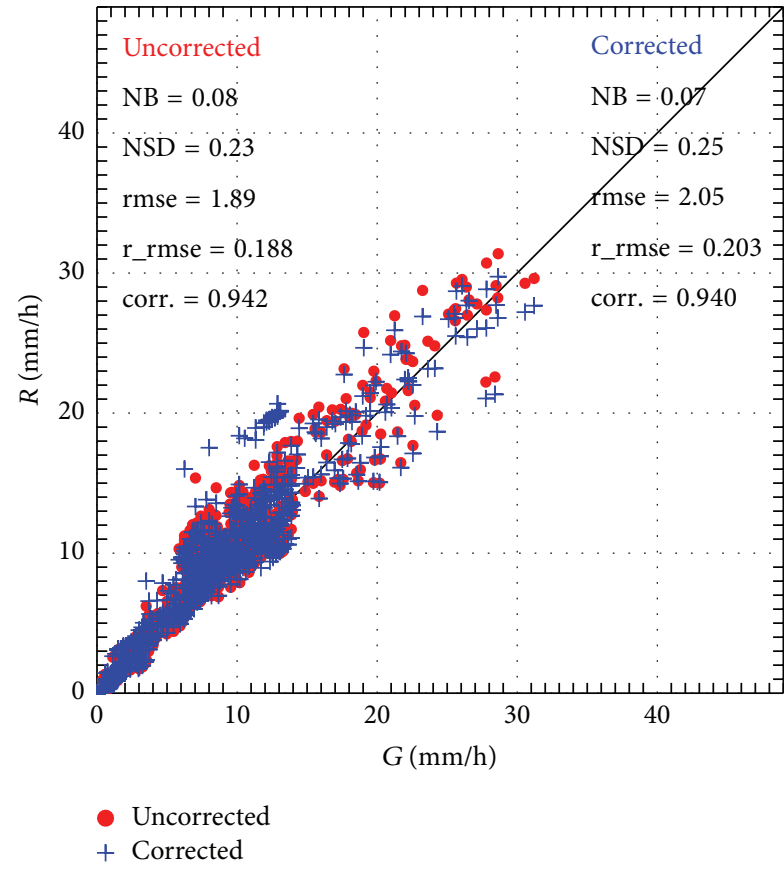

(b) $R\left(Z_{H}, Z_{\mathrm{DR}}\right)$

FigURE 18: The scatter plots of $R\left(0.38 \mathrm{~km}^{2}, 60 \mathrm{~min}\right)$ versus $G\left(0.07 \mathrm{~m}^{2}, 60 \mathrm{~min}\right)$ (a) using $Z_{H}$ and (b) using $Z_{H}$ and $Z_{\mathrm{DR}}$.

and $32 \%$ at $10 \mathrm{~min}$ accumulation, respectively. At $60 \mathrm{~min}$ accumulation, the NB, NSD, rmse, and r_rmse were decreased from $-65 \%, 86 \%, 7.1(\mathrm{~mm} / \mathrm{hr})$, and $70 \%$ to $-5 \%, 34 \%$, $2.8(\mathrm{~mm} / \mathrm{hr})$, and $28 \%$, respectively. Using $R\left(Z_{H}, Z_{\mathrm{DR}}\right)$, the $\mathrm{NB}, \mathrm{NSD}$, rmse, and r_rmse were only slightly reduced even if attenuation was corrected but were smaller than when using $R\left(Z_{H}\right)$. This indicated that $R\left(Z_{H}, Z_{\mathrm{DR}}\right)$ was less sensitive to the attenuation than $R\left(Z_{H}\right)$. In addition, half of the errors that remained after attenuation correction were caused by the small scale variability of the rain fields and the instrumental 


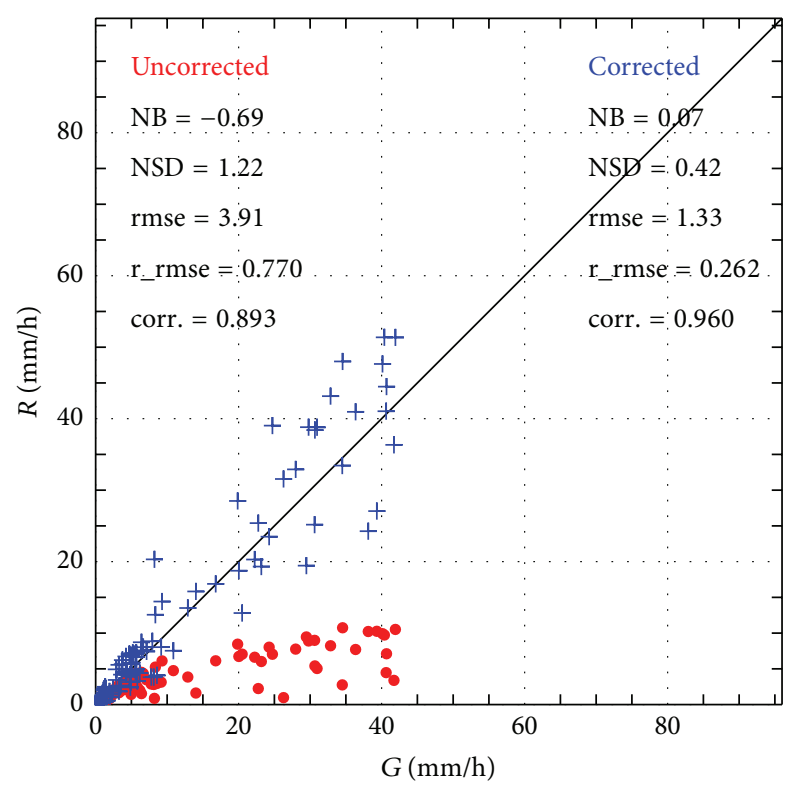

- Uncorrected

+ Corrected

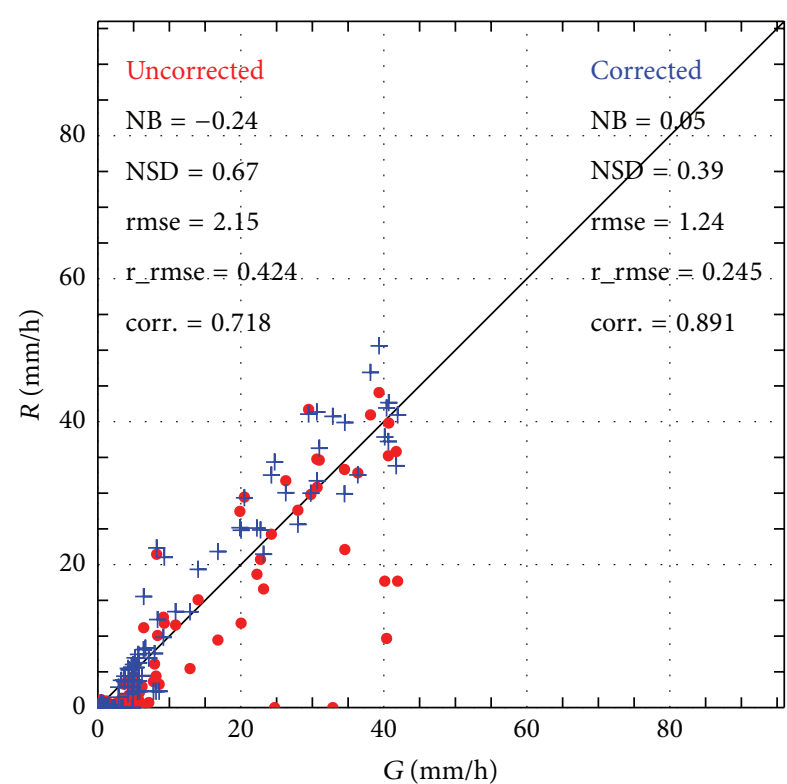

- Uncorrected

+ Corrected

(a) $R\left(Z_{H}\right)$

(b) $R\left(Z_{H}, Z_{\mathrm{DR}}\right)$

FIgURE 19: The scatter plots of $R\left(6 \mathrm{~km}^{2}, 10 \mathrm{~min}\right)$ versus $G\left(6 \mathrm{~km}^{2}, 10 \mathrm{~min}\right)$ (a) using $Z_{H}$ and (b) using $Z_{H}$ and $Z_{\mathrm{DR}}$.

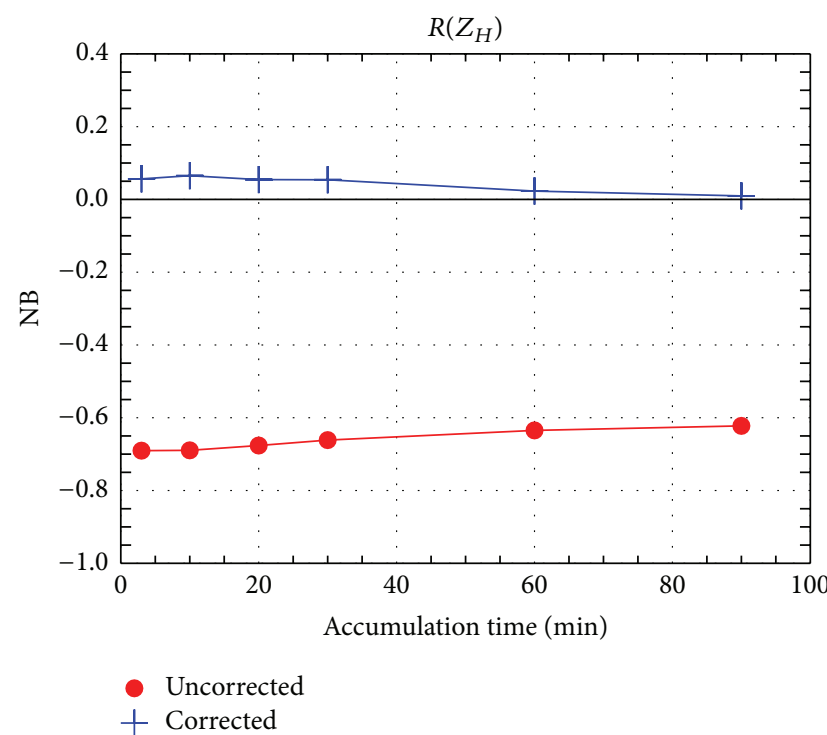

(a) $R\left(Z_{H}\right)$

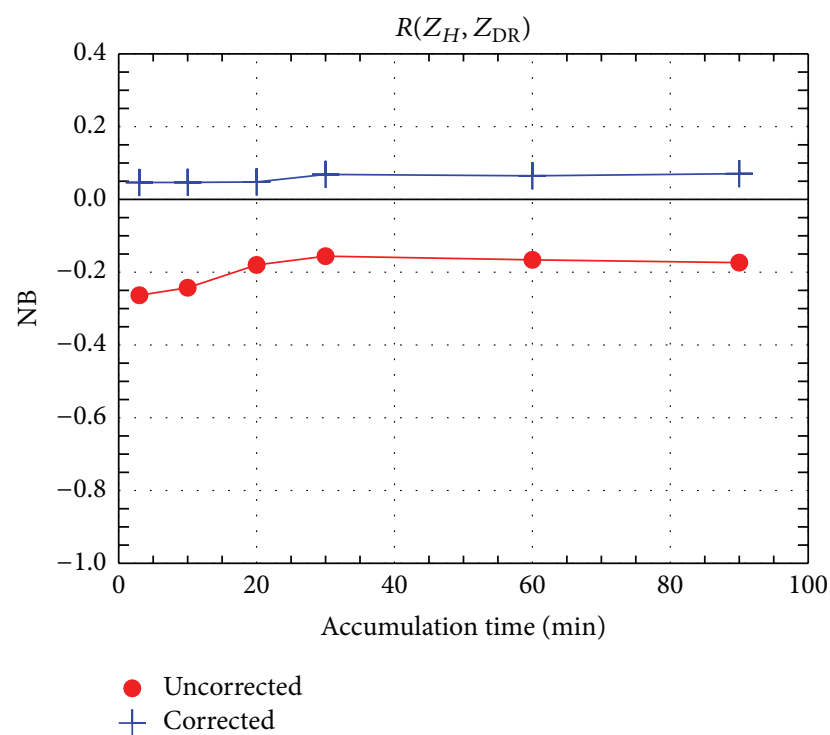

(b) $R\left(Z_{H}, Z_{\mathrm{DR}}\right)$

Figure 20: The normalized bias of $R\left(6 \mathrm{~km}^{2}\right)$ versus $G\left(6 \mathrm{~km}^{2}\right)$ with an accumulation time (a) using $Z_{H}$ and (b) using $Z_{H}$ and $Z_{\mathrm{DR}}$. The red point-line and the blue point-line indicate without and with the attenuation correction, respectively.

uncertainty of the rain gauges. Using an areal averaged value, the NB was reduced to less than $7 \%$ with attenuation correction using either rainfall estimator, regardless of accumulation time. The $r_{-}$rmse were significantly reduced by attenuation correction in $R\left(Z_{H}\right)$, and the reduction of r_rmse with $R\left(Z_{H}, Z_{\mathrm{DR}}\right)$ was even more dramatic.
As summarized above, the rain attenuation for $Z_{H}$ and $Z_{\mathrm{DR}}$ in the X-band was corrected by $\Phi_{\mathrm{DP}}$, and the results showed a good agreement with the value obtained by scattering simulations with the DSD datasets. The results of comparison with rain gauge data also showed a significant improvement in the accuracy of rainfall estimation by 


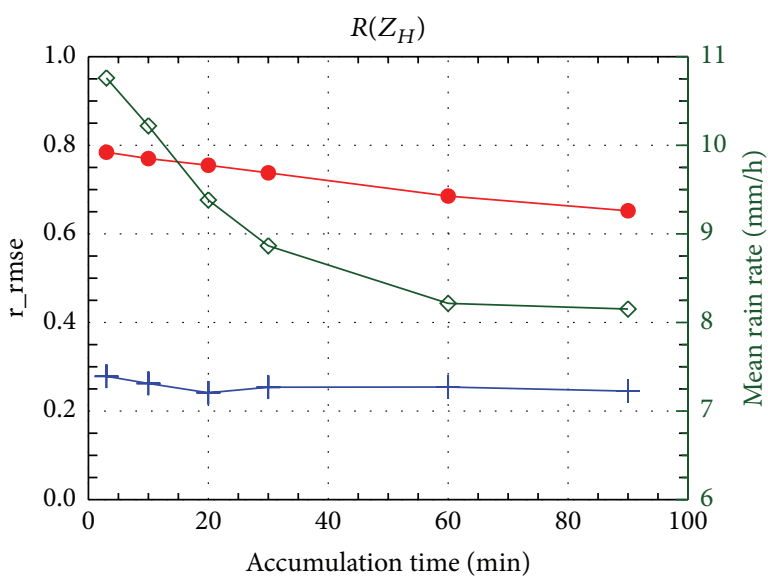

- Uncorrected

+ Corrected

$\diamond$ Mean $R$

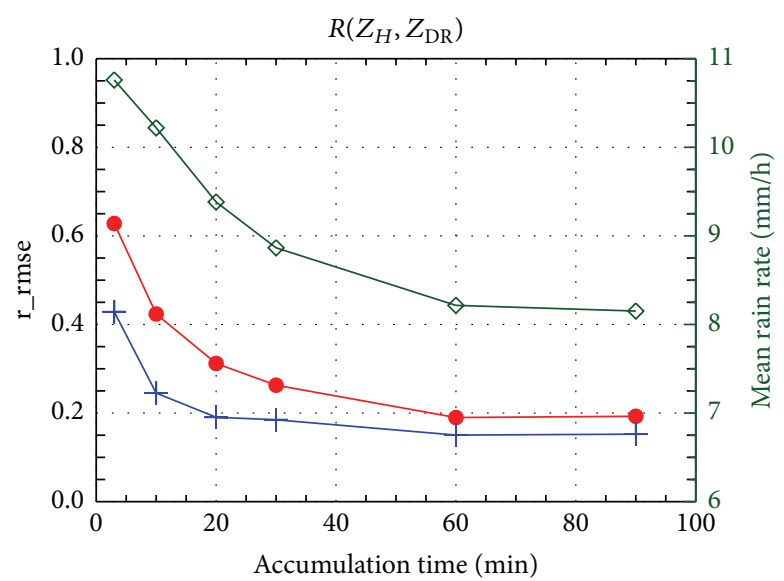

- Uncorrected

+ Corrected

$\diamond$ Mean $R$

(a) $R\left(Z_{H}\right)$

(b) $R\left(Z_{H}, Z_{\mathrm{DR}}\right)$

FIGURE 21: The relative root-mean square error of $R\left(6 \mathrm{~km}^{2}\right)$ versus $G\left(6 \mathrm{~km}^{2}\right)$ with an accumulation time (a) using $Z_{H}$ and (b) using $Z_{H}$ and $Z_{\mathrm{DR}}$. The red point-line and the blue point-line indicate without and with the attenuation correction, respectively.

attenuation correction, which supports the quantitative use of the X-band radar in rain data retrieval.

\section{Appendix}

\section{A. Instrumental Uncertainty of the Rain Gauge}

The instrumental uncertainty of the TB rain gauge is associated with improper calibration, leakage and precipitation missing the gauge due to the measurement principle, and wetting and evaporation losses. In addition, external sources, such as wind, turbulence, and installed position, also contribute to the instrumental uncertainty. Ciach [17] reported that the TB gauge data suffers a significant uncertainty associated with random differences between closely collocated TB gauges through the analysis of the error as a function of the rainfall intensity for three timescales. In addition, the improper calibration induces a bias in the rainfall measurement, and this bias cannot be removed by increasing accumulation time. Therefore, the proper correction or processing of TB gauge data is necessary to obtain accurate and reliable reading of the rainfall amount.

In this appendix, instrumental biases were calculated to reduce the instrumental uncertainty through an ideal experiment in the laboratory and a field intercomparison with $10 \mathrm{~TB}$ rain gauges. In addition, the random errors were quantitatively calculated as a function of rainfall rate and accumulation time.

A.1. Correction of Instrumental Bias. The instrumental bias $B_{I}(i)$ of the $i$ th gauge was defined as a combination of the absolute bias $B_{A}(\mathrm{ref})$ of the reference gauge and the relative bias $B_{R}(i)$ of the $i$ th gauge according to the following equation:

$$
B_{I}(i)=B_{A}(\mathrm{ref}) \times B_{R}(i) .
$$

$B_{A}($ ref $)$ signified the ratio of the calculated value from the instrumental resolution of the reference gauge to the true value measured by other instruments:

$$
B_{A}(\text { ref })=\frac{\text { rainfall }_{\text {truth }}}{\text { rainfall }_{\text {gauge }}(\text { ref })} .
$$

In this study, $B_{A}$ (ref) was derived by an ideal experiment using an electronic scale. First, the reference gauge was put on the scale, and the scale was initialized. The water drops flowed out into the receiving orifice of the reference gauge until the tipping number became 60 . The measured weight of 60 tips was $214.4 \mathrm{~g}$, while the theoretical (or expected) value was $224.4 \mathrm{~g}$ for the reference gauge (receiving orifice size of $15.45 \mathrm{~cm}, 60$ tips, and $0.2 \mathrm{~mm}$ tip resolution). Therefore, the absolute bias of the reference gauge from (A.2) was about 0.955 . This indicates that the rainfall amount measured by this reference gauge was overestimated by about $4.5 \%$, and this bias should be corrected prior to any interpretation.

$B_{R}(i)$ represented the ratio of the observed (recorded) value from the $i$ th gauge to the observed (recorded) value from the reference gauge:

$$
B_{R}(i)=\frac{\text { rainfall }_{\text {gauge }}(\text { ref })}{\text { rainfall }_{\text {gauge }}(i)} .
$$

$B_{R}(i)$ was calculated from ten collocated rain gauges including the reference gauge, located at an observation field 
TABLE 4: The instrumental and relative biases of the 10 tipping bucket rain gauges.

\begin{tabular}{lllllllllll}
\hline Gauge ID & RG1 & RG2 & RG3 & RG4 & RG5 & RG6 & RG7 & RG8 & RG9 & RG10 \\
\hline Instrumental bias & 0.94 & 1.08 & 0.99 & 1.00 & 0.96 & 1.04 & 0.98 & 1.02 & 1.08 & 0.98 \\
\hline Relative bias & 0.98 & 1.13 & 1.03 & 1.05 & 1.00 & 1.09 & 1.02 & 1.07 & 1.13 & 1.02 \\
\hline
\end{tabular}

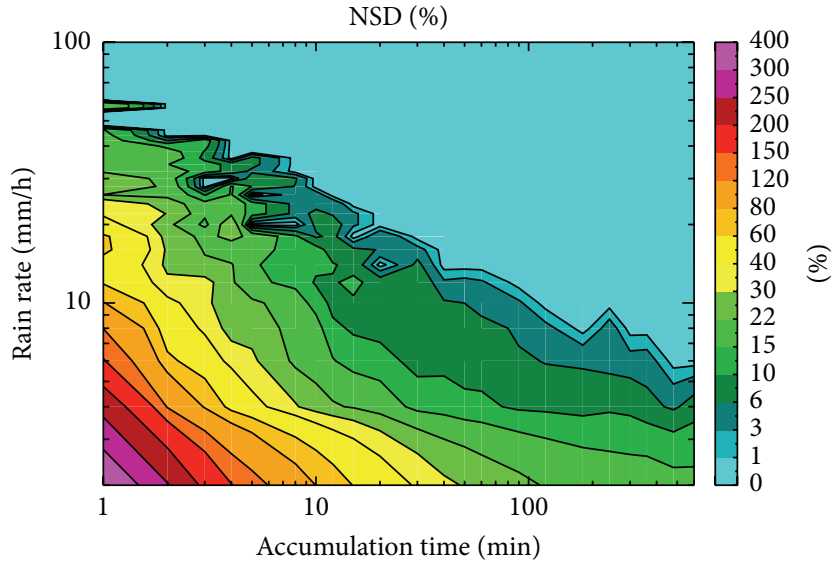

FIgURE 22: Two-dimensional normalized standard deviation between the standard rainfall and each rain gauge.

at KNU, Korea. The observational period for intercomparison was from October 2009 to June 2010 (14 rainy days), and the total accumulated rainfall for this period was about $300 \mathrm{~mm}$. The results are presented in Table 4. All relative biases were mainly larger than 1.0. This indicated that the most of gauges underestimated the rainfall amount compared to the reference rain gauge. The relative bias of the reference gauge $(i=5)$ was 1.0.

Finally, $B_{A}(i)$ was calculated from (A.1) (see Table 4). All instrumental biases were between 0.90 and 1.1, and the mean value of the biases was nearly 1.0. This indicated that the rainfall rate from a single gauge data had a maximum $10 \%$ bias. These biases were corrected for each gauge to remove existing instrumental errors.

A.2. Quantification of Random Errors. To quantify the random error due to instrumental uncertainty, the NSD of the ten gauges was calculated with accumulation time and rain rate using data from an intercomparison. The NSD of the $i$ th gauge compared to the reference gauge was derived for 20 rain rate classes $(\Delta R)$ and 17 accumulation time classes $(\Delta t)$ as follows:

$$
\begin{aligned}
\operatorname{NSD}_{i}(\Delta t, \Delta R) \\
=\frac{(1 / n) \sqrt{\sum_{k=0}^{n-1}\left[G_{K}^{\prime}(\Delta t, \Delta R)-G_{i k}(\Delta t, \Delta R)\right]^{2}}}{\overline{G^{\prime}}},
\end{aligned}
$$

where $G^{\prime}$ and $G$ indicate the reference and individual gauges, respectively. The overbar means the temporal average of the rainfall rate. The NSDs of nine different gauges (except the reference gauge) were averaged to obtain the twodimensional average NSD (Figure 22). The average NSD tended to decrease with increasing accumulation time and with increasing rain rate. The NSD was about $10-15 \%$ when accumulation time was $10 \mathrm{~min}$ and the rain rate was $10 \mathrm{~mm} \mathrm{~h}^{-1}$. The instrumental errors were quite significant for longer accumulation times and higher rainfall rates. These errors should be used as a guideline when a single gauge is used as a reference for any validation study.

\section{Competing Interests}

The authors declare that they have no competing interests.

\section{Acknowledgments}

This paper has been revised and extended from Ms. Young-A Oh's M.S. thesis [25] of Kyungpook National University. This research is supported by Development and Application of Cross Governmental Dual-Pol Radar Harmonization (WRC2013-A-1) project of the Weather Radar Center, Korea Meteorological Administration. This work was funded by the Korea Meteorological Administration Research and Development Program under Grant KMIPA2015-1010.

\section{References}

[1] V. N. Bringi, V. Chandrasekar, N. Balakrishnan, and D. S. Zrnić, "An examination of propagation effects in rainfall on radar measurements at microwave frequencies," Journal of Atmospheric and Oceanic Technology, vol. 7, no. 6, pp. 829-840, 1990.

[2] A. Huggel, W. Schmid, and A. Waldvogel, "Raindrop size distributions and the radar bright band," Journal of Applied Meteorology, vol. 35, no. 10, pp. 1688-1701, 1996.

[3] G. W. Lee, Errors in rain measurement by radar: effect of variability of drop size distributions [Ph.D. thesis], McGill University, 2003.

[4] J. D. Tuttle and R. E. Rinehart, "Attenuation correction in dualwavelength analyses," Journal of Climate \& Applied Meteorology, vol. 22, no. 11, pp. 1914-1921, 1983.

[5] S.-G. Park, V. N. Bringi, V. Chandrasekar, M. Maki, and K. Iwanami, "Correction of radar reflectivity and differential reflectivity for rain attenuation at X band. Part I: theoretical and empirical basis," Journal of Atmospheric and Oceanic Technology, vol. 22, no. 11, pp. 1621-1632, 2005.

[6] G. Scarchilli, E. Gorgucci, V. Chandrasekar, and T. A. Seliga, "Rainfall estimation using polarimetric techniques at C-band frequencies," Journal of Applied Meteorology, vol. 32, no. 6, pp. 1150-1160, 1993.

[7] M. N. Anagnostou, E. N. Anagnostou, and J. Vivekanandan, "Correction for rain path specific and differential attenuation of X-band dual-polarization observations," IEEE Transactions on Geoscience and Remote Sensing, vol. 44, no. 9, pp. 2470-2480, 2006. 
[8] J. Kalogiros, M. N. Anagnostou, E. N. Anagnostou, M. Montopoli, E. Picciotti, and F. S. Marzano, "Evaluation of a new polarimetric algorithm for rain-path attenuation correction of $\mathrm{X}$-band radar observations against disdrometer," IEEE Transactions on Geoscience and Remote Sensing, vol. 52, no. 2, pp. 13691380, 2014.

[9] W.-Y. Chang, J. Vivekanandan, and T.-C. C. Wang, "Estimation of X-band polarimetric radar attenuation and measurement uncertainty using a variational method," Journal of Applied Meteorology and Climatology, vol. 53, no. 4, pp. 1099-1119, 2014.

[10] J. Hubbert and V. N. Bringi, "An iterative filtering technique for the analysis of copolar differential phase and dual-frequency radar measurements," Journal of Atmospheric and Oceanic Technology, vol. 12, no. 3, pp. 643-648, 1995.

[11] K. V. Mishra, W. F. Krajewski, R. Goska et al., "Deployment and performance analyses of high-resolution iowa XPOL radar system during the NASA IFloodS campaign," Journal of Hydrometeorology, vol. 17, no. 2, pp. 455-479, 2016.

[12] M. Thurai, G. J. Huang, V. N. Bringi, W. L. Randeu, and M. Schönhuber, "Drop shapes, model comparisons, and calculations of polarimetric radar parameters in rain," Journal of Atmospheric and Oceanic Technology, vol. 24, no. 6, pp. 10191032, 2007.

[13] M. D. Humphrey, J. D. Istok, J. Y. Lee, J. A. Hevesi, and A. L. Flint, "A new method for automated dynamic calibration of tipping-bucket rain gauges," Journal of Atmospheric and Oceanic Technology, vol. 14, no. 6, pp. 1513-1519, 1997.

[14] E. Habib, W. F. Krajewski, V. Nespor, and A. Kruger, "Numerical simulation studies of rain gage data correction due to wind effect," Journal of Geophysical Research Atmospheres, vol. 104, no. 16, Article ID 1999JD900228, pp. 19723-19733, 1999.

[15] G. J. Ciach and W. F. Krajewski, "On the estimation of radar rainfall error variance," Advances in Water Resources, vol. 22, no. 6, pp. 585-595, 1999.

[16] E. Habib, W. F. Krajewski, and A. Kruger, "Sampling errors of tipping-bucket rain gauge measurements," Journal of Hydrologic Engineering, vol. 6, no. 2, pp. 159-166, 2001.

[17] G. J. Ciach, "Local random errors in tipping-bucket rain gauge measurements," Journal of Atmospheric and Oceanic Technology, vol. 20, no. 5, pp. 752-759, 2003.

[18] E. Habib, W. F. Krajewski, and G. J. Ciach, "Estimation of rainfall interstation correlation," Journal of Hydrometeorology, vol. 2, no. 6, pp. 621-629, 2001.

[19] NIMS, "Study on estimation of rainfall amount and classification of hydrometeor species using dual-polarimetric radar (III)," pp. 1-20, 2010.

[20] E. Gorgucci, V. Chandrasekar, and L. Baldini, "Correction of $\mathrm{X}$-band radar observation for propagation effects based on the self-consistency principle," Journal of Atmospheric and Oceanic Technology, vol. 23, pp. 1668-1681, 2006.

[21] NIMS, "Study on estimating raindrop size distribution for quantitative estimation of radar rainfall amount," pp. 1-55, 2009.

[22] NIMS, "Quantitative precipitation estimation and hydrometeor identification using dual-polarization radar-Phase II," pp. 1-74, 2009.

[23] S.-G. Park, M. Maki, K. Iwanami, V. N. Bringi, and V. Chandrasekar, "Correction of radar reflectivity and differential reflectivity for rain attenuation at X band. Part II: Evaluation and application," Journal of Atmospheric and Oceanic Technology, vol. 22, no. 11, pp. 1633-1655, 2005.
[24] E. Habib and W. F. Krajewski, "Uncertainty analysis of the TRMM ground-validation radar-rainfall products: application to the TEFLUN-B field campaign," Journal of Applied Meteorology, vol. 41, no. 5, pp. 558-572, 2002.

[25] Y.-A. Oh, Rainfall estimation from X-band dual-polarization radar measurements: effects of attenuation correction and evaluation with a dense rain gauge network [M.S. thesis], Kyungpook National University, 2011. 

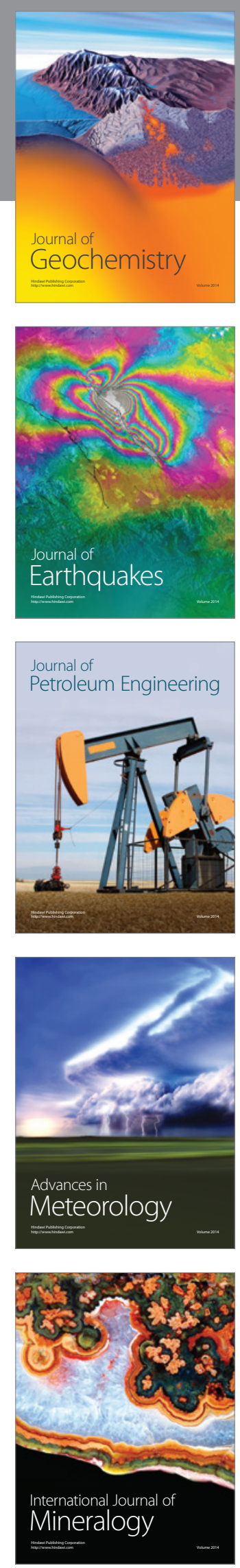
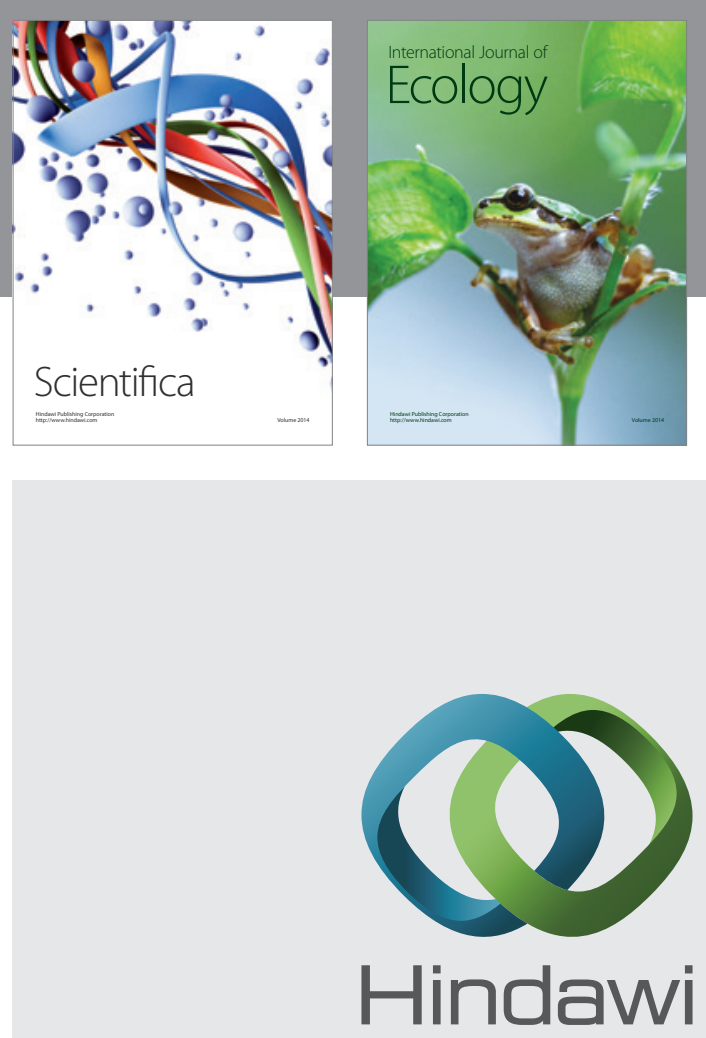

Submit your manuscripts at

http://www.hindawi.com
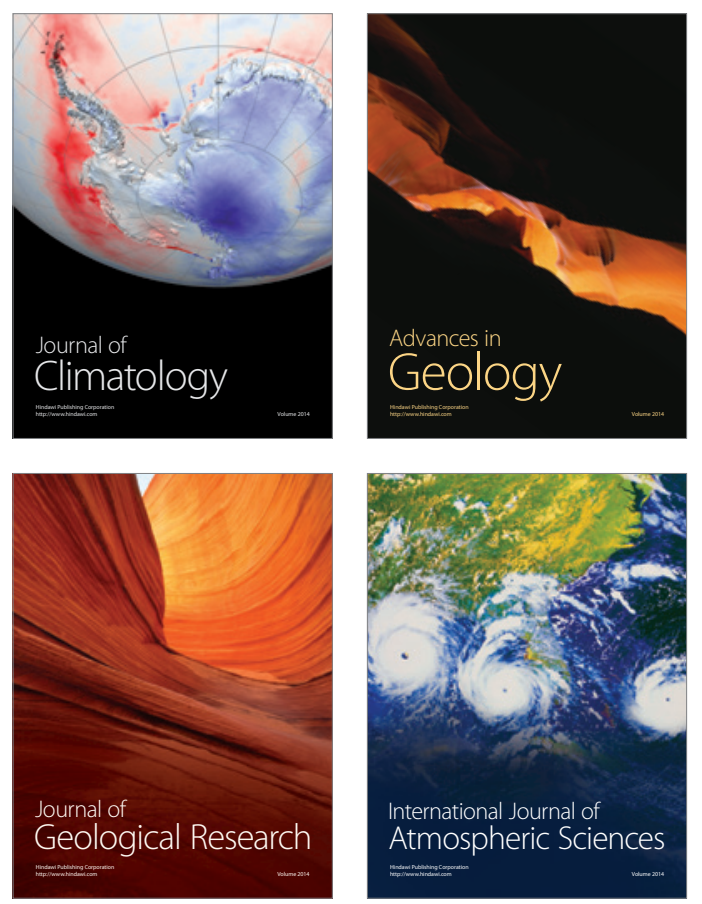

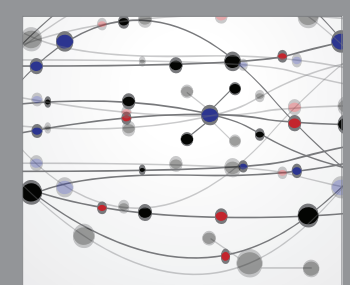

The Scientific

\section{World Journal}
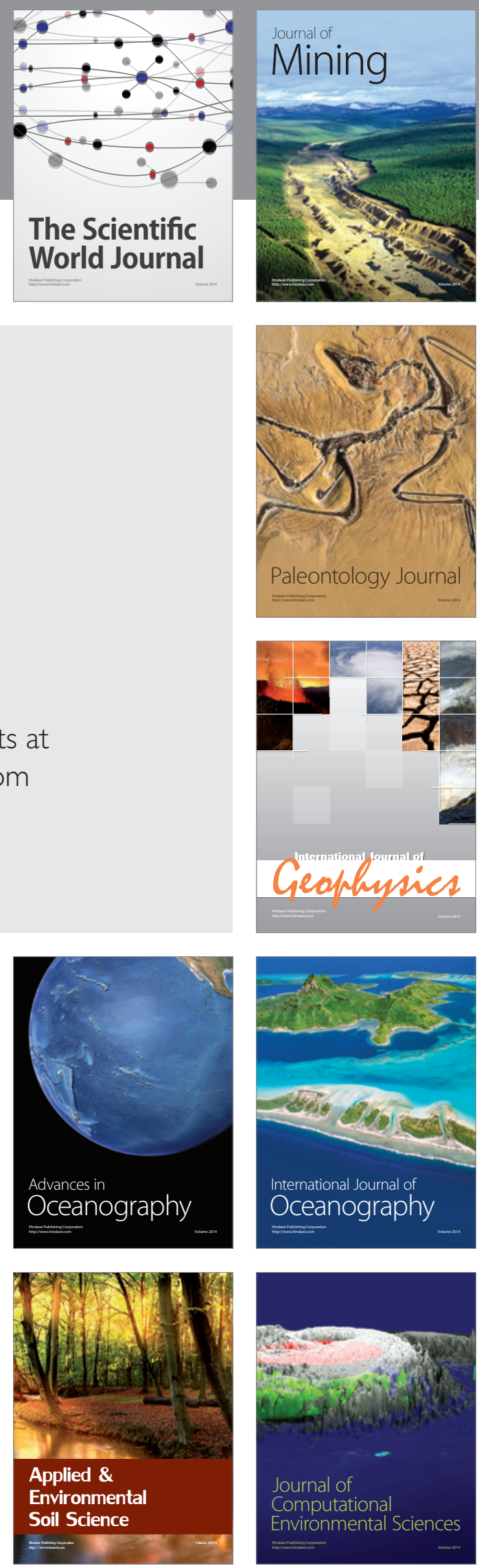